NASA Technical Memorandum 106864

\title{
Experimental Technique and Assessment for Measuring the Convective Heat Transfer Coefficient From Natural Ice Accretions
}

K. Cyril Masiulaniec

University of Toledo

Toledo, Ohio

G. James Van Fossen, Jr.

Lewis Research Center

Cleveland, Ohio

Kenneth J. DeWitt and Nihad Dukhan

University of Toledo

Toledo, Ohio

Prepared for the

33rd Aerospace Sciences Meeting and Exhibit

sponsored by the American Institute of Aeronautics and Astronautics

Reno, Nevada, January 9-12, 1995

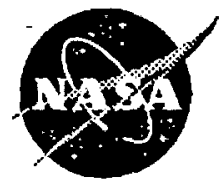

National Aeronautics and Space Administration

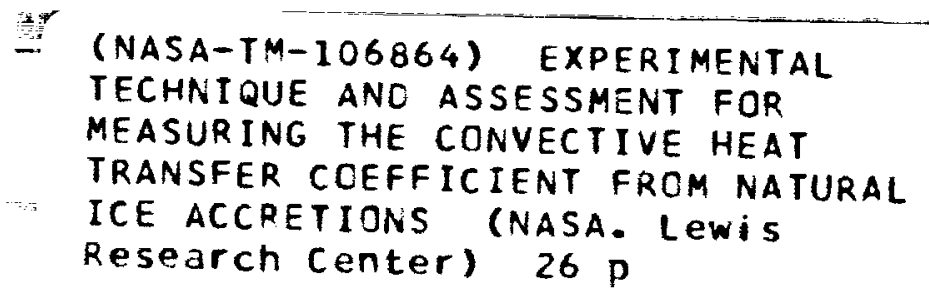

N95- 23248

TECHNIQUE ANO ASSESSMENT FOR

MEASURING THE CONVECTIVE HEAT

TRANSFER COEFFICIENT FROM NATURAL

ICE ACCRETIONS (NASA.

Unclas 


\title{
EXPERIMENTAL TECHNIQUE AND ASSESSMENT FOR MEASURING THE CONVECTIVE \\ HEAT TRANSFER COEFFICIENT FROM NATURAL ICE ACCRETIONS
}

\author{
K. Cyril Masiulaniec, University of Toledo, Toledo, Ohio * \\ G. James Van Fossen, Jr., NASA LeRC, Cleveland, Ohio † \\ Kenneth J. DeWitt, University of Toledo, Toledo, Ohio ¥ \\ Nihad Dukhan, University of Toledo, Toledo, Ohio §
}

\begin{abstract}
A technique was developed to cast frozen ice shapes that had been grown on a metal surface. This technique was applied to a series of ice shapes that were grown in the NASA Lewis Icing Research Tunnel on flat plates. Nine flat plates, 18 inches square, were obtained from which aluminum castings were made that gave good ice shape characterizations. Test strips taken from these plates were outfitted with heat flux gages, such that when placed in a dry wind tunnel, can be used to experimentally map out the convective heat transfer coefficient in the direction of flow from the roughened surfaces. The effects on the heat transfer coefficient for both parallel and accelerating flow will be studied. The smooth plate model verification baseline data as well as one ice roughened test case are presented.
\end{abstract}

\section{Nomenclature}

$\begin{array}{ll}\text { A } & \text { surface area of gage, } \mathbf{m}^{2} \\ \mathbf{k} & \text { thermal conductivity of air, W/m-K } \\ \mathrm{M} & \text { mesh spacing of bars in turbulence grid, } \mathrm{cm} \\ \mathrm{Pr} & \text { Prandtl number } \\ \mathrm{q} & \text { heat flow, } \mathrm{W} \\ \mathrm{Re} & \text { Reynolds number } \\ \mathrm{r}(\mathrm{s}) & \text { local recovery factor } \\ \mathrm{St} & \text { Stanton number } \\ \mathrm{T} & \text { temperature, } \mathrm{K} \\ \mathrm{Tu} & \text { turbulence intensity } \\ \mathbf{u} & \text { mean velocity, } \mathrm{m} / \mathrm{s} \\ \mathbf{X} & \text { streamwise distance, } \mathrm{m} \\ \xi & \text { fraction of gage thickness from heater to } \\ & \quad \text { thermocouple } \\ \tau & \text { thickness, } \mathrm{m}\end{array}$

* Assoc. Prof., Mech. Engr., Member AIAA.

† Senior Research Sci., Member AIAA.

₹ Professor, Chem. Engr., Member AIAA.

$\S$ PhD Graduate Student
Subscripts

\begin{tabular}{ll} 
Alum & aluminum \\
conv & convection \\
EI & electrical heating \\
epoxy & epoxy between gage and bottom guard \\
gap & bottom guard heater \\
Kap & Kapton material \\
$\mathbf{r}$ & recovery \\
rad & radiation \\
s & surface of gage \\
st & static \\
$\mathbf{t}$ & total \\
TC & thermocouple \\
w & wall \\
$\mathbf{x}$ & streamwise direction \\
$\infty$ & free stream \\
\hline
\end{tabular}

\section{Introduction}

The primary objective of this experimental work is to have an accurate determination of the values of the convective heat transfer coefficient , $\mathrm{h}$ ", at the surface of an accreted ice shape. These values are needed to improve numerical ice shape predictions as well as electrothermal deicer performance using simulation codes.

One of the codes that simulates ice accretion along with electrothermal deicer performance is LEWICE, developed by the Icing and Cryogenics Technology Branch at NASA-LeRC. The LEWICE code currently uses heat transfer coefficients obtained from an integral boundary layer technique, which are subsequently corrected or adjusted for a non-smooth surface using an equivalent sand-grain roughness approach. The integral boundary layer method being used, as well as the equivalent sand-grain roughness adjustment, are based primarily on empirical relationships which are driven by the computed velocities (from an Euler code) at the top of the momentum boundary layer. It has become apparent in using LEWICE to simulate certain types of ice 
accretions that the current empirical relationships need to be refined or replaced with relationships that give more representative or physically correct values of " $h$ ". To achieve this, a more fundamental understanding is needed of the effect of the special types of surface roughness observed on accreting ice shapes.

\section{The Roughness Problem}

For any flow field, both the fluid dynamics and the thermal characteristics are strongly affected by the surface condition of a solid wall. This phenomenon becomes particularly important in applications where roughness is an inherent feature. Because of their frequent occurrence in practice, rough surfaces have gained a lot of engineering interest and received prolonged serious study. Examples include missiles, heat exchangers, pipes, turbine blades, naval architecture, aeronautics, nuclear reactor applications, and recently aircraft components in icy conditions. The NASA Space Shuttle Program studied roughness as it affects augmented heating. Whether or not rough surfaces are advantageous for engineering use depends on the specific application.

Both heat transfer and skin friction are usually higher for a turbulent flow over a rough surface compared with an equivalent flow over a smooth surface. Serious engineering investigations focused on the development of accurate predictive models for heat transfer and fluid mechanics in turbulent flow over rough surfaces. In order to come up with such models, comprehensive sets of experimental data for a range of roughness conditions were needed. Those data sets had to include the effects of roughness geometrical shapes, sizes, distributions, and whether the roughness character is uniform or random.

The types of roughness investigated varied as have also the flow geometries and configuration. Machined threads, wires close to the surface, spheres, hemispheres, cones, pyramids, humps, angles, transverse bars, cylinders, half cylinders and sand grains, are some of the roughness elements that have been studied.

\section{Earlv Studies}

The pioneering work of Nikuradse [1933] marks the beginning of the experimental study of the effect of surface roughness on the fluid flow. He studied the effect of coarse and fine roughness on water flow in pipes of different diameters using actual sand grains.
Reynolds numbers ranged from $10^{4}$ to $10^{6}$. To correlate his roughness effects, he used relative roughness defined as the ratio of the height of any roughness element (absolute roughness) to the pipe radius. Experimental data were obtained for six different degrees of relative roughness. Quantities measured were loss of pressure head, velocity distribution in the stream immediately after leaving the pipe, and discharge quantity. Nikuradse identified three flow regimes based on what he termed the roughness Reynolds number given by $\operatorname{Re}_{\mathbf{k a}}=\frac{\mathbf{u}^{*} \mathbf{k}_{\mathrm{s}}}{\mathrm{v}}$ where $u^{*}=\sqrt{\frac{\tau_{0}}{r}}$ is the friction velocity and $k_{z}$ is the size of the sand grains. These three regimes were

$$
\begin{array}{lrl}
\text { aerodynamically smooth } & \operatorname{Re}_{\mathrm{ks}}<5 \\
\text { transitionally rough } 5 & <\operatorname{Re}_{\mathrm{ks}}<55-70 \\
\text { fully rough } & \operatorname{Re}_{\mathrm{ks}} & >55-70 .
\end{array}
$$

In the first regime, the roughness elements were supposedly contained entirely within the viscous sublayer and the skin friction coefficient was independent of the roughness but dependent on the Reynolds number of the gross flow. In the transition range, the roughness elements protruded through the sublayer and the friction coefficient was a function of both the Reynolds number and the relative roughness. The friction coefficient increased with increasing Reynolds number. Finally, in the fully rough pipe flow, the sublayer is effectively destroyed and the skin friction coefficient depended only on the relative roughness and was independent of the Reynolds number. The three regions identified apply not only to sand roughness but also to many other kinds of roughness elements used in practice.

From a practical point of view, the third region where the flow is entirely turbulent is the most important and Schlichting's investigations [1936] were mainly concerned with this region. To incorporate more of the actual physics into the correlations, Schlichting used two parameters to characterize roughness: the absolute roughness that was used by Nikaradse, and the roughness density which is the number of roughness elements per unit area. The experiments were conducted in a rectangular channel. The types of roughness investigated were twenty-one flat, rough plates installed as the top side of a channel. The three other walls of the channel were smooth. The roughness elements included spheres of diameter $0.41 \mathrm{~cm}$, cones and short and long angles. The 
absolute roughness or roughness height $k$ was 2 to 4 $\mathrm{cm}$. The pattern of roughness was the same while the roughness density was varied. In order to apply his results to channels and pipes of other hydraulic radii and to towed plates, Schlichting had to determine an equivalent sand roughness $\mathbf{k}_{\mathbf{s}}$. This roughness was the grain size of the sand roughness as used in the test of Nikuradse and had the same resistance as the corresponding roughness elements at the same Reynolds number based on the hydraulic radius. As expected, besides depending on the relative roughness, the frictional resistance depended also on the second roughness parameter, namely the roughness density $\frac{F_{z}}{F}$ where $F_{z}$ was the total projected area of the roughness elements onto a plane normal to the direction of the flow and $F$ is the plate area. The maximum resistance did not occur at the maximum roughness density but at a considerably lower value.

For a few years after (up to 1951), only a limited number of roughness studies were carried out. One of these was by W. F. Moore. [1951], who presented experimental velocity profiles, surface resistance, turbulent intensity, and shear stress for zero-pressuregradient flow over a flat plate with two-dimensional roughness elements (transverse bars.)

In subsequent surface roughness investigations, authors used Nikuradse's and Schlichting's results along with the equivalent sandgrain roughness concept to analyze their experimental data and in developing analytical models. Over the years, several correlations (Dvorak [1969]; Simpson [1973]; Dirling [1973]) were developed which produced a value of the equivalent sandgrain roughness for a rough surface whose geometrical description was known.

The problem of the effect of roughness on heat transfer received less attention. One of the first studies concerning heat transfer from the rough surface of a tube was conducted by Cope [1941]. Smith and Epstein [1957] presented heat transfer and fluid friction measurements for air flow in commercial pipes with a ratio of diameter to equivalent sandgrain roughness varying from 640 to 64 . The Reynolds number ranged from 10,000 to 80,000 . A very thorough study largely involving two-dimensional roughness elements was published by Nunner [1958].

Due to the coupled nature of the momentum and heat transfer problem, later investigations usually considered both the fluid mechanics and the heat transfer interactions due to roughness. That consideration facilitated the interpretation of experimental results and provided hints on how to correlate, present, and compare them.

Dipprey and Sabersky [1963] presented semitheoretical arguments along with experimental results for the relation between heat transfer and friction in smooth and rough tubes. Three rough wbes and a smooth one were investigated. The rough tubes had a closed-packed, granular surface with roughness-todiameter ratios ranging from 0.0024 to 0.049 . The Prandtl number ranged from 1.20 to 5.94. The Reynolds numbers ranged from $6 \times 10^{4}$ to $5 \times 10^{5}$ and from $1.4 \times 10^{4}$ to $1.2 \times 10^{5}$ at the lowest and the highest Prandtl numbers, respectively. Increases in the heat transfer coefficient due to roughness of as high as 270 per cent were obtained. These increases were, in general, accompanied by even larger increases in the friction coefficient. An exception to this behavior occurred at high Prandtl number in the region of transition. It was stated that the Stanton number decreased monotonically in the fully rough region.

Perry and Joubert [1963] studied the effect of roughness using plates with a traverse length of $17 \mathrm{ft}$ in a wind tunnel having an adverse pressure gradient. The roughness consisted of 800 strips of timber which were $5 \mathrm{ft}$ and 3 in long. The spacing to height ratio then was 4 . They stated that the effect of roughness on the flow away from a rough wall can be accounted for by using an equivalent viscosity $v_{e}$. The effect of roughness on the velocity profile shape therefore was, like viscosity, confined to a thin layer adjoining the rough surface. This layer was about $15 \%$ of the well known boundary layer thickness. The equivalent viscosity depended only on variables at the wall such as shear stress $\tau_{0}$, fluid density $p$, viscosity $\mu$, and the roughness size and geometry. The shear velocity $u_{\tau}$ was given by $u_{\tau}=\sqrt{\frac{\tau_{\rho}}{\rho}}$. By dimensional reasoning $\frac{v_{e}}{v}=f\left(\frac{k u_{\tau}}{V}\right)$ where $k$ is any length scale associated with the roughness size. For low values of $\frac{k_{\tau}}{v}, v_{e}$ was equal to $v$, meaning roughness had no effect (the smooth regime). 
However, for high values of $\frac{\mathrm{ku}_{\tau}}{\mathrm{v}}$ (rough regime), $\mathrm{v}_{\mathrm{e}}$ was independent of the pressure gradients imposed and was given by $v_{e}=a k u_{\tau}$ where a was a constant dependent on the roughness geometry. It was also stated that the relationship among these variables was the same for both boundary layer and duct flow.

Seban [1964] reported experimental results regarding the local heat transfer coefficient from a flat bakelite plate with a step in the surface. The boundary layer separated at 1 inch downward from the step and reattached downstream. Velocity and temperature distributions in the separated and the reattached regions were also presented for constant heat flux at the wall. The plate was the top surface of a rectangular channel. It was 12.0 inches wide and 18.0 inches long. Seban suggested that heat transferred from the wall to the reverse flow in the separated region was retained in the reverse flow until that flow joined the free shear layer in the region near the step. From the velocity profiles, it was evident that the local heat transfer coefficient diminished after reattachment.

Sherif and Gumley [1960] experimentally investigated heat transfer and friction characteristics of a surface with discrete roughness. They proposed a two-layer model of the heat transfer resistance. The heat transfer process was subdivided into a region from the wall to the envelope enclosing the roughness tips, and a central core region. The heat transfer resistance from the wall to the roughness tips had a minimum value (which produced an optimum heat transfer surface) at $\mathrm{e}^{+}=35$ where $\mathrm{e}^{+}=\mathrm{e} \sqrt{\frac{\tau \nu}{\rho}}$ and $e$ is the roughness height.

Sood and Johnson [1969] gave some correlation's for the resistance to heat and momentum transfer in the viscous sublayer on a rough wall for flows of different geometries. Yaglom and Kader [1974] developed analytical expressions for heat and mass transfer quantities between a rough wall and turbulent fluid flow at high Reynolds and Peclet numbers. Their investigations were applicable for a wide range of Reynolds numbers, Prandtl numbers, and roughness sizes and shapes. Lewis. [1975] presented an analytical model which approximated the turbulent flow over a well-defined rough surface. The flow was represented by a series of attached and separated flow regions.

\section{Studies at Stanford University}

A series of experimental studies of the effect of roughness on the fluid dynamics and heat transfer in turbulent boundary layers was conducted at Stanford University during the 1970's by Healzer [1974], Pimenta [1975,] Coleman [1976], and Ligrani [1979]. These data sets included velocity, temperature, and Reynolds stress profiles. However, these data sets were for a single rough surface comprised of spheres of the same size packed in a dense array and thus did not provide information on the effect of different roughness shapes and spacing.

Coleman [1976] investigated experimentally the behavior of the fully rough turbulent boundary layer subject to favorable pressure gradients using a porous test surface composed of densely packed spheres of uniform size. Profiles of mean velocity, mean temperature, and the components of the Reynolds stress tensor were reported. A new acceleration parameter was defined and was shown to be dependent on the roughness size but independent of molecular viscosity. For fully rough flow, acceleration caused an increase in the Stanton number. The possibility of having an equilibrium thermal state for the case of constant wall temperature was stressed. This state would be characterized by similar temperature profiles in the flow direction and a constant Stanton number.

\section{More Resent Studies}

Christoph and Pletcher [1983] provided a finite diference solution to the boundary-layer equations for flow over rough surfaces. The equations were cast to account for the blockage effect of the roughness elements.

Scaggs, Taylor, and Coleman [1988] presented experimental results of the effect of surface roughness on the turbulent pipe flow friction factor. Eleven different rough surfaces were used, nine of which had uniform roughness elements and two had non-uniform roughness. The data covered a range of element size, spacings, and shapes. Pipe Reynolds number ranged from $10^{4}$ to $6 \times 10^{6}$.

Taylor et al. [1988] presented experimental Stanton number results for a turbulent incompressible flat plate boundary layer with a variety of thermal boundary conditions: constant wall temperature, constant wall heat flux, and linear wall temperature variations. Coleman et al. [1988] provided 
information regarding the heat transfer from a smooth plate for air flow at up to a Reynolds number of 10 million. Uncertainty analysis, design, and qualification of a heat transfer test facility in the urbulent regime were given.

Hosni, Colman, and Taylor [1991] gave predictions and measurements of the effect of surface roughness on a turbulent rough-wall boundary layer. The cases considered are constant wall temperature, constant wall heat flux, step wall temperature, and piecewise linear wall temperature distributions. Some accelerated flow cases were also investigated. A modified roughness energy transport model for the discrete element prediction method was presented. The same authors [1991] reported experimental results of Stanton number for aerodynamically smooth, transitionally rough, and fully rough turbulent boundary layer flows over three rough surfaces and a smooth one. The rough surfaces were composed of $1.27 \mathrm{~mm}$ diameter hemispheres spaced in staggered arrays 2, 4, and 10 base diameters apart. Flow conditions gave Reynolds numbers up to $10^{7}$. It was shown that the asymptotic behavior of the heat transfer data is not in general a valid measure for classification of rough-wall flow regimes, as was proposed previously.

Taylor et al. [1992] presented Stanton number distributions and boundary layer profiles of mean temperature, mean velocity, and aurbulence intensity for a surface with a step change from rough to a smooth surface. In most cases, the Stanton number immediately downstream of the change in roughness drops below the all-smooth-wall data at the same local Reynolds number.

Hosni et al. [1993] reported Stanton number and skin friction coefficient results for zero pressure gradient incompressible turbulent boundary layer air flows over two rough surfaces. The rough surfaces were composed of $1.27 \mathrm{~mm}$ base diameter by 0.635 $\mathrm{mm}$ high truncated cones spaced in staggered arrays two and four diameters apart on an otherwise smooth wall. The data showed definitive differences when compared to hemispherical roughness under similar flow conditions. No dependence of skin friction coefficients on roughress element shape could be concluded.

\section{Numerical Solutions and the Discrete Element} Method

All calculation methods that use the sandgrain roughness approach must distinguish between the three regimes because different models are required. This adds to the burden of predetermination of the state of the flow.

Coleman, Hodge, and Taylor [1984] showed that Schlichting had made erroneous assumptions during his data reduction. It was shown that his skin friction results were too large by amounts ranging up to $73 \%$ and his reported equivalent sand grain roughness values were high by amounts ranging from $26 \%$ to $555 \%$.

Over the past decade, a predictive approach has been developed called the discrete element method. This method does not use the equivalent sand grain roughness concept but rather relies on empirical input to calibrate the roughness models. The physical effects of the roughness on the flow field are modeled by considering the blockage effect of the roughness elements and the drag forces which the roughness elements exert on the fluid and also the heat transfer between the roughness elements and the flow. The method was used by several groups of researchers, namely Finson [1975]; Adams and Hodge [1977]; Finson and Wu [1979]; Finson and Clark [1980]; Lin and Bywater [1980]; Finson [1982]; and Taylor, Coleman, and Hodge [1983, 1985].

The discrete element approach incorporates more basic physics of the process and uses a more generalized empirical input. It is therefore applicable to a broader spectrum of surfaces without requiring surface-specific experimental data. The basic idea is to formulate a system of partial differential equations that describes the mass, momentum, and energy transport for the flow over, around, and between the roughness elements. In this method, the roughness effects are taken as an integral part of the flow problem and not (as with the equivalent sandgrain approach) as some ill-defined boundary condition. For more information about this method see Taylor, Colman and Hodge [1984, 1985]. As derived, the method abandons the roughness Reynolds number as the definition for smooth, transitional, and fully rough flow conditions. 


\section{Ice-Roughness Studies}

The degradation in aerodynamic performance of aircraft due to ice accretion in regions of cooler climate include added weight, lift reduction, drag increase, and possibly flight control problems. Another problem is the impact of shed ice on aircraft components such as blades and rotors.

The two methods employed to counter ice accretion are anti-icing and de-icing. Anti-icing uses heat to prevent ice from forming. De-icing is removing ice shortly after it begins to grow. This is accomplished by melting or mechanically cracking the ice. In order to utilize these methods, it is crucial to have a reliable way of predicting the ice growth.

Understanding of airfoil ice accretion characteristics and resultant degradation in aerodynamic performance relies usually on experimental tests in an icing simulation facility. A good part of the available data was gathered by NASA researchers in the NASA Icing Research Tunnel between 1940 and 1960 for both military and commercial transport applications.

Some experimental studies regarding the effect of ice roughness on heat transfer were conducted as part of the NASA Icing Research Program. It was shown that the ice shapes change drastically for different conditions. Existing codes show that the predicted ice shapes are very sensitive to the assumed heat transfer coefficient. In order to correct this problem, this investigation aims to provide data concerning the heat transfer coefficient from different ice shapes.

Shaw, Sotos, and Solano [1982] studied icing and resultant aerodynamic performance characteristics due to rime and glaze icing conditions using a NASA $63_{2}$ 2415 airfoil section. Experiments were carried out for both climb and cruse aerodynamics conditions. Results included drag coefficients and ice accretion measurements.

Van Fossen et al. [1984] presented experimental values of the heat transfer coefficient from irregular cylindrical shapes which typify the accretion of ice on a circular cylinder in crossflow. Poinsatte [1990] presented experimental heat transfer data from a smooth and roughened NASA 0012 airfoil for Reynolds numbers in the range $1.24 \times 10^{6}$ to $2.50 \times$ $10^{6}$ and various angles of attack up to 4 degrees. Roughness was obtained by attaching $2 \mathrm{~mm}$ diameter hemispheres. Four patterns were chosen. The roughness drastically increased the heat transfer.

\section{Investment Castings of Natural Ice Shapes}

A technique was developed at the University of Toledo to cast frozen ice shapes that had been grown on a metal surface. The substrate consisted of a ceramic powder commencially known as 'Refracto Mix \#1'. This powder is specifically designed for use in investment castings where fine detail transfer from the investment to the cast is critical, and it is specifically formulated for aluminum alloys as the cast material. Because of the need for casting at subfreezing temperatures, the mold slurry needed to be at the same subfreezing temperatures as the ice accretions. Ethanol was eventually chosen as the most suitable fluid for the slurry. The binding agent was silica that was colloidally suspended in the ethanol. The silica in the silica-ethanol suspension was $20 \%$ of the suspension by weight. Just before pouring the slurry over an ice shape to be cast, ammonium hydroxide was added to the mix as the catalyst so that the silica binder would solidify. The amount of the catalyst had to be carefully controlled, so that there was sufficient time for the slurry to pour to capture the ice shape, yet solidify as quickly as possible to ensure as accurate a casting of the ice shape as possible. The amount of time between adding the catalyst to when a complete, rock-hard set was attained was approximately 45 seconds.

Once the casting was obtained, it was immediately placed in a freezer and allowed to sit for two days to insure a complete cure. The casting was then removed from the freezer and allowed to come to room temperature, at which point the ice melted and was poured from the casting. The castings were then baked for 8 hours in a high temperature oven to drive off any water or ethanol that might be in the mold . Just before the casting itself was made, the ceramic molds were heated to about 800 degrees Fahrenheit, just before the molten aluminum was poured. This insured that the aluminum remained moiten for a period of time, and not immediately solidify, so as to capture as much of the microscopic surface detail as possible. After solidification, a high pressure water jet was used to remove all traces of the mold material from the aluminum. After all nine plates were examined and it was decided which sections test specimens were to come from, a wire EDM machine was used to drop out the test tiles. This device was used to ensure clean cuts with no disturbance of the surface characteristics, while at the same time 
maintaining very close tolerances. This can easily be done since the wire EDM makes the cuts by vaporizing the metal around the wire, so it never comes into contact with the metal itself, thus eliminating the possibility of any tooling/cutting marks at the surface which might alter the surface geometry and hence the final results.

The above techniques were then applied to a series of ice shapes that were grown in the NASA-LeRC's Icing Research Tunnel on flat plates. Nine flat plates, 18 inches by 18 inches, were obtained that characterized a number of different types of ice accretions from which castings were made. The different types of accretions can be loosely characterized as: closely spaced rough glaze, loosely spaced rough glaze, closely spaced mildly rough glaze, smooth glaze, smooth rime, rime with small feathers and rime with very large feathers.

\section{Construction of Heat Transfer Model}

Figures 1 through 3 depict the manner in which the heat transfer model was designed and assembled. The model consists of two parts, the test bed and the saddle. The test bed is in essence a large composite of many heat flux gages and guard heaters, as can be seen in Figure 1. The test bed consists of a center row of test tiles, each being approximately 0.5 inches in the flow direction and 1.25 inches perpendicular to the flow, and 0.5 inches deep. These test tiles were EDM cut from the aluminum castings of the ice shapes. Along side these test tiles are guard tiles, four on either side, also EDM cut from the aluminum castings. Care was taken to ensure as much similarity as possible in the type of roughness at the surface of the guard heaters to maintain surface flow symmetry on either side of the test tiles. The test tiles and side guard tiles were all instrumented with thermocouples to measure their temperatures as shown in Figure 3. Biot number computations show that each tile may be assumed to have essentially a constant temperature throughout. Kapton encased thin foil heating elements were then affixed to the bottom surfaces of all the center tiles and side guard tiles. These provided the heat source to elevate the center test tiles above ambient temperature, whose measurement was subsequently used to back out the average value of the heat transfer coefficient for the upward projected area of the tile. The test tiles and guard tiles were assembled one at a time with an insulative epoxy and spacing shims to ensure a uniform gap between all of the tiles at the top surface, and to thermally isolate all of the tiles from each other.
This top surface was then epoxied to a large bottom plate fabricated from 0.5 inch thick aluminum plate. The epoxy thickness was approximately 0.125 inches. This plate serves as the bottom guard plate to prevent conduction downward, as well as providing a very solid base to support the tiles above. A large Kapton encased foil heater was affixed to the bottom of this plate.

The foil heaters kept all the tiles and the bottom plate as nearly at the same temperature as possible. Thus, virtually all of the heat being generated by the center tiles would be directed upward into the air stream. It should be noted that the first and last tiles in the center test strip are really acting in the capacity of guard heaters, and thus should not be included in the experimental data set from the test runs.

An intermediary structure, being called the saddle, interfaces the test bed with the wind tunnel test section. Adjustable struts mounted between the bottom of the saddle and the test section floor permitted accurate placement/alignment of the test bed for the parallel and accelerating flow cases. Circular disks mounted to the sides of the saddle toward the end of the saddle fixed this end, and permitted rotation using this as a pivot point when the struts were adjusted. These circular disks were actually part of the test section's two side walls, and sat within two openings in the wall, thus being integral with the wall. The saddle cavity was designed such that the thermocouple leads and heater power leads could be fed through a contained cavity, and out through the side disks to the data acquisition system input ports. Expandable foam insulation was then injected into this cavity to further insulate the test bed from the saddle and the test section air flow. The test bed itself was held in place with four pins driven through and flush with the sides of the saddle, with four rubber pads near the sides of the top surface to center the test bed in the saddle and to prevent the side guard tiles from touching the edges of the saddle.

The front part of the saddle, as can be seen in Figure 2, is outfitted with a noseblock, the upper surface of which is a 10:1, one-sixteenth inch thick ellipse. This was needed to ensure a smooth uniform airflow onto the test bed. Without this, a separation bubble would form at the leading edge of the test bed, and reattach downstream. This does introduce the difficulties associated with an unheated starting length in the thermal convective problem, but could not be avoided. 


\section{Wind Tunnel}

The experiments were carried out in the wind tunnel shown in Figure 4. Air drawn from the test cell passed through a flow-conditioning section and a 4.85: 1 contraction before entering the $15.2-\mathrm{cm}$-wide by $68.6-\mathrm{cm}$-high test section. The maximum velocity attainable was about $46 \mathrm{~m} / \mathrm{sec}$. Clear tunnel turbulence levels were less than 0.5 percent. After leaving the test section, the air passed through a transition section into a 10-in. pipe in which a flowmeasuring orifice and a butterfly valve were located. Four thermocouples around the perimeter of the inlet measured the stagnation temperature.

\section{Data Acquisition and Reduction}

Steady-state operating conditions (temperatures, pressures, gage voltages and currents, etc.) were recorded on the laboratory data acquisition system called ESCORT (Miller, [1980]). An energy balance was solved to determine the Stanton number for each gage:

$$
S t(x)=\frac{\left(q_{E I}-q_{2 d}-q_{g}-q_{\text {gand }}\right) x}{A\left[T_{3}-T_{\gamma}\right] k \operatorname{Re}_{\text {in, }, x} \operatorname{Pr}}
$$

where $\mathrm{q}_{\mathrm{ET}}$ is the heat added to the gage by the heater, $q_{\text {ad }}$ is the heat lost by radiation, $q_{u p}$ is the heat convected away from the epoxy gap between the gages, $\mathrm{q}_{\text {gand }}$ is the heat conducted from the gage to the guard heater under the gage, ' $x$ ' is the distance to the gage measured from the leading edge of the plate, ' $A$ ' is the exposed gage surface area, $T_{1}$ is the gage surface temperature, $T_{x}$ is the local recovery temperature , ' $k$ ' is the thermal conductivity of the air evaluated at the film temperature, $\mathbf{R e}_{\text {in, } x}$ is the Reynolds number based on the inlet velocity and distance from the leading edge, and 'Pr' is the Prandt number of the air.

Corrections for radiation heat loss, $q_{\ldots}$, were made assuming gray body radiation to black surroundings and an emissivity of 0.05 for the aluminum gage. An estimate of the gap loss, $q_{\text {ap }}$, can be obtained from an exact solution for twodimensional heat conduction in a rectangle (see Van Fossen et al. [1984] for details).

At high heat fluxes a significant temperature gradient developed between the heater and the imbedded thermocouple. This made it impossible to adjust the bottom guard temperature to match the heater temperature, thus allowing a small amount of heat, $q_{\text {gad }}$, to leak to the bottom of the guard. This was accounted for by assuming one-dimensional heat conduction and calculating the heater temperature, $\mathrm{T}_{\mathrm{bx}}$, as

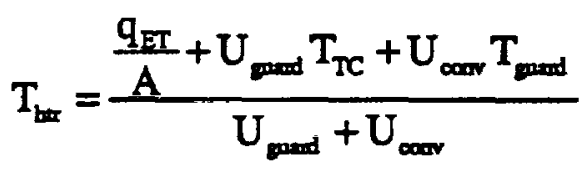

where

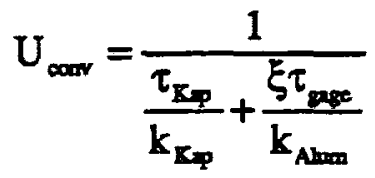

and

$$
U_{\text {puxd }}=\frac{1}{\frac{\tau_{\mathrm{kP}_{p}}}{k_{\mathrm{k}_{p}}}+\frac{\tau_{\text {paxy }}}{k_{\text {qpaxy }}}}
$$

where $T_{T C}$ and $T_{\text {anew }}$ are the measured thermocouple and guard temperatures, $\tau_{K_{p}}$ is the thickness of the Kapton film encapsulating the foil heater, $k_{K_{p}}$ is the thermal conductivity of Kapton, $\tau_{\text {in }}$ is the thickness of the aluminum gage, $k_{\text {Amm }}$ is the conductivity of the aluminum, $\tau_{\text {coxy }}$ is the thickness of the epoxy layer separating the gage and the grard plate, and $\mathbf{k}_{\text {epaxy }}$ is the conductivity of the epoxy. The heat leaked to the guard heater was then

$$
q_{\text {gand }}=U_{\text {mad }} A\left(T_{\text {ber }}-T_{\text {maxd }}\right)
$$

The gage surface temperature, $T_{a}$, was similarly calculated as

$$
T_{s}=T_{T C}-\frac{\tau_{\text {poxy }} q_{\text {oxav }}(1-\xi) \tau_{\text {gare }}}{k_{\text {Abro }} A}
$$

The gap loss, $q_{2 p}$, was about 2 percent of the total heat flow, the loss to the bottom guard, $\mathrm{q}_{\text {gurd }}$, was also about 2 percent while the radiation loss, $q_{p d}$, was on the order of 0.2 percent.

The recovery temperature was calculated as 


$$
T_{r}=T_{x,-\infty}+\sqrt{\operatorname{Pr}}\left(T_{t}-T_{x,-\infty}\right)
$$

where $T_{a,-}$ is the static temperature upstream of the model. The Reynolds number, $\operatorname{Re}_{\mathrm{in}, \mathrm{x}}$, was based on the distance from the leading edge, $x$, and the inlet velocity.

\section{Results}

The results for the cases that were tested can be divided into two parts, a series of verification runs using a flat plate model to duplicate classical results, and the a series of runs with the first ice roughened model, with the roughness characterized as rough glaze with closely spaced ice nodules. Figures 5 through 13 represent the smooth flat plate cases, and Figures 14 through 22 represent the ice roughened cases.

For both sets of cases, free-stream velocities at the inlet of approximately $31,68,107$ and 155 feet per second were used, for angles of 5, 14, 23, 32, and 41 degrees. The test bed at 5 degrees was used as the parallel flow case. This was done to insure that any slight imperfections at the surface, or any misalignment problems between the test bed and the saddle, did not trip the laminar boundary layer prematurely. This is represented as the 0.0 degree case in the results.

Figures 5 through 8 show the results for a fixed orientation to the flow with varying velocities. Figure 5 is for the parallel flow case, and agrees well with the classical solution for laminar flow over a smooth flat plate for all velocities. At the higher velocities, the Stanton number clearly shows transition to turbulent flow occurring around the expected value of a Reynolds number of 500,000 . The theoretical solutions shown include the effect of an unheated starting length. Figures 6 through 8 show the effect of accelerating flow at different angles, and are compared to Schlichting's classical wedge solutions for this problem. As can be seen, there is good agreement, with the experimental data lying above the wedge solutions. This is to be expected, since the wedge solutions assume an infinite medium, and the tunnel test section has an upper wall. Thus, the flow will accelerate a little faster, resulting in higher velocities and thus higher heat transfer coefficients. Schlichting's wedge solutions also do not account for an unheated starting length. From the heat transfer data, it appears that the flow is beginning to transition at different Reynolds numbers, where the transition point moves downstream as velocity increases. This effect becomes increasingly pronounced as the test bed angle increases.

Figures 9 through 13 replot the experimental results for a smooth flat plate for different test bed angles holding the free stream velocity constant. The theoretical curve shown on these plots is for the smooth flat plate parallel to the flow. From these plots, it can be seen that the flow seems to transition further upstream as the angle increases, with the effect becoming less pronounced as the velocity increases. As velocity continues to increase, an 'inflection' point is apparently reached where this effect is reversed, and the opposite trend is seen, which becomes more pronounced as the velocity continues to increase. There appears to be two physical phenomena interacting, where as velocity is increased, one begins to gradually dominate the other.

Figures 14 through 18 show the experimental results of the ice roughened case for different velocities holding the test bed angle fixed. For the parallel flow case, the results appear to form a single curve. As the test bed angle increases, a family of curves based on velocity becomes increasingly more pronounced, clearly showing the effect that accelerating flow has on the Stanton number.

Figures 19 through 22 replot the same data holding the velocity fixed as the test bed angle is increased. As can be seen, there is a difference in the Stanton number. at the beginning of the test bed, where the Stanton number. decreases as the test bed angle increases. On all four plots, the Stanton numbers appear to merge to form a single cure as the Reynolds number increases, making the Stanton number independent of test bed angle.

\section{Concluding Remarks and Recommendations}

This effort is the first attempt to provide experimental data on the convective heat transfer coefficient over ice-roughened surfaces. It will provide a useful benchmark for ice accretion and electrothermal deicer performance codes in the numerical prediction of these values. Test results from the other aluminum castings of ice roughnesses need to obtained before general conclusions can be drawn. 


\section{Acknowledements}

The authors wish to extend their appreciation to the Icing and Cryogenics Technology Branch at the NASA Lewis Research Center, Cleveland, Ohio, for funding this work under NASA Grant NAG 3-72, and to Dr. Jaiwon Shin, the grant monitor. The authors also wish to extend their appreciation to the Heat Transfer Branch at the NASA Lewis Research Center for use of their wind tunnel and data acquisition facilities for the aluminum ice models.

\section{References}

Miller, R.L., "ESCORT: A Data Acquisition and Display System to Support Research Testing," NASA TM-78909, 1987.

Lewis, M. J., "An Elementary Analysis for Predicting the Momentum - and Heat - Transfer Characteristics of Hydraulically Rough Surfacen, J. of Heat Transfer, May 1975.

Christoph, George H. and Pletcher, Richard H., "Prediction of Rough - Wall Skin Friction and Heat Transfer", ALAA Joumal, April 1983.

Von Fossen, G. J., Simoneau, R. J., Olsen, W. A. Jr., and Shaw, R. J., "Heat Transfer Distributions Around Nominal Ice Accretion Shapes formed on a Cylinder in the NASA Lewis Icing Research Tunnel", AIAA 22nd Meeting, January 9-12, 1984.

Hosni, M. H., Coleman, Hugh W., and Taylor, Robert P., "Measurements and Calculations of Rough - Wall Heat Transfer in the Turbulent Boundary Layer", Int. J. of Heat and Mass Transfer, 1991.

Hosni, M. H., Coleman, Hugh W., and Taylor, Robert P., "Calculations of Rough - Wall Heat Transfer in the Turbulent Boundary Layer", AIAA Meeting, January 7-10, 1991.

Hosni, M. H., Coleman, Hugh W., Gamer, James W, and Taylor, Robert P., "Roughness Element Shape Effected on Heat Transfer and Skin Friction in Rough - Wall Turbulent Boundary Layer", Int. J. of Heat and Mass Transfer, 1993.

Yang-Moon koh, "Turbulent Flow Near A Rough Wall;", J. of Fluids Engineering, December, 1992.
Taylor, Robert P., Coleman, Hugh W., Hosni, M. H., and Love, Phillip H., "Thermal Boundary Condition Effects on Heat Transfer in the Turbulent Incompressible Flat Plate Boundary Layer", Int. J. of Heat and Mass Transfer, Vol. 23, 1989.

Taylor, Robert P., Taylor, J. Keith, Hosni, M. H., and Coleman, Hugh W., "The Turbulent Thermal Boundary Layer with an Abrupt Change from as Rough to a Smooth Wall", Int. J. of Heat and Mass Transfer, 1993.

Dipper D. F., and Saber sky, R. H., "Heat and Momentum Transfer in Smooth and Rough Tubes at Various Prandtl Numbers", Int. J. of Heat and Mass Transfer, Vol. 6, 1963, pp 329-353.

Wilkie, D., "Forced Convection Heat Transfer from Surfaces Roughened by Transverse Ribs", I. Mech. E. Int. Heat Transfer Conference, Chicago, Vol. 3, 1966.

Seben, R. A., "Heat Transfer to the Turbulent Separated Flow of Air Downstream of a Step in the Surface of a Plate", J. of Heat Transfer, Trans. ASME, Series C, Vol. 86, No. 2, May 1964, pp. 259-264.

Shaw, R. J., Sotos, R. G., and Solano, F. R., "An Experimental Study of Airfoil Icing Characteristics", NASA TM 82790, 1982.

Perry, A. E., and Joubert P. N., "Rough - Wall Boundary Layers in Adverse Pressure Gradients", J. Fluid Mech. 17, pp 193-211, (1963).

Cebeci, T., and Chang K. C., "Calculation of Incompressible Rough - Wall Boundary - Layer Flows", ALAA J. 16, 730-735, (1978).

Scaggs, W. F., Taylor, R. P. and Coleman, H. W., "Measurements and Prediction of Rough Wall Effects on Friction Factor in Turbulent Pipe Flow", Report TFD-88-1, Mech. and Nucl. Engrg. Dept, Mississippi State University (1988).

Finson, M. L., and Wu, P. K. S., "Analysis of Rough Wall Turbulent Heating with Application to Blunted Flight Vehicles", AIAA Paper 79-008, (1979).

Sood, N. S., and Johnson, V. K., "Some Correlations for Resistances to Heat and Momentum Transfer in the Viscous Sublayer at Rough Walls", Trans. ASME J. of Heat Transfer, pp 484-494, (1969). 
Yaglom, A. M., and Kader B. A., "Heat and Mass Transfer Between a Rough Wall and a Turbulent Fluid Flow at High Reynolds and Peclet Number", J. Fluid Mech. 62, pp 601-623, (1974).

Smith, J. W., and Epstein, N., "Effect of Wall Roughness on Convective Heat Transfer in Commercial Pipes", J. AI CHE 3, pp 242-248, (1957).

Moore, W. F., "An Experimental Investigation of the Boundary Layer Development Along a Rough Surface", Ph.D. Dissertation, State University of Iowa, 1951.

Owen, P. R, and Thomson, W. R, "Heat Transfer Across Rough Surfaces," Joumal of Fluid Mechanics, Vol. 15, 1963, pp. 321-334.

Sherif, N., and Gumley, P., "Heat Transfer and Friction Properties of Surface with Discrete Roughnesses," International joumal of Heat and Mass Transfer, Vol. 9, 1966

Orlando, A. F.,"Turbulent Transport of Heat and Deceleration, Suction and Variable Wall Temperature," Ph.D. Dissertation, Mec. Eng. Dep., Stanford Univ. (1974).

Coleman, H. W.,"Momentum and Energy Transport in the Accelerated Fully Rough Turbulent Boundary Layer," Ph. D. Dissertation, Department of Mechanical Engineering, Stanford University (1976)

Pimenta, M.,"The Turbulent Boundary Layer. An Experimental Study of the Transport of Momentum and Heat with the Effect of Roughness," Ph. D. Dissertation, Department of Mechanical Engineering, Stanford University (1975)

Poinsatte, P. E., "Heat Transfer Measurements from a NASA 0012 Airfoil in Flight and in the NASA Lewis Icing Research Tunnel," MS thesis, the University of Toledo, 1989. 


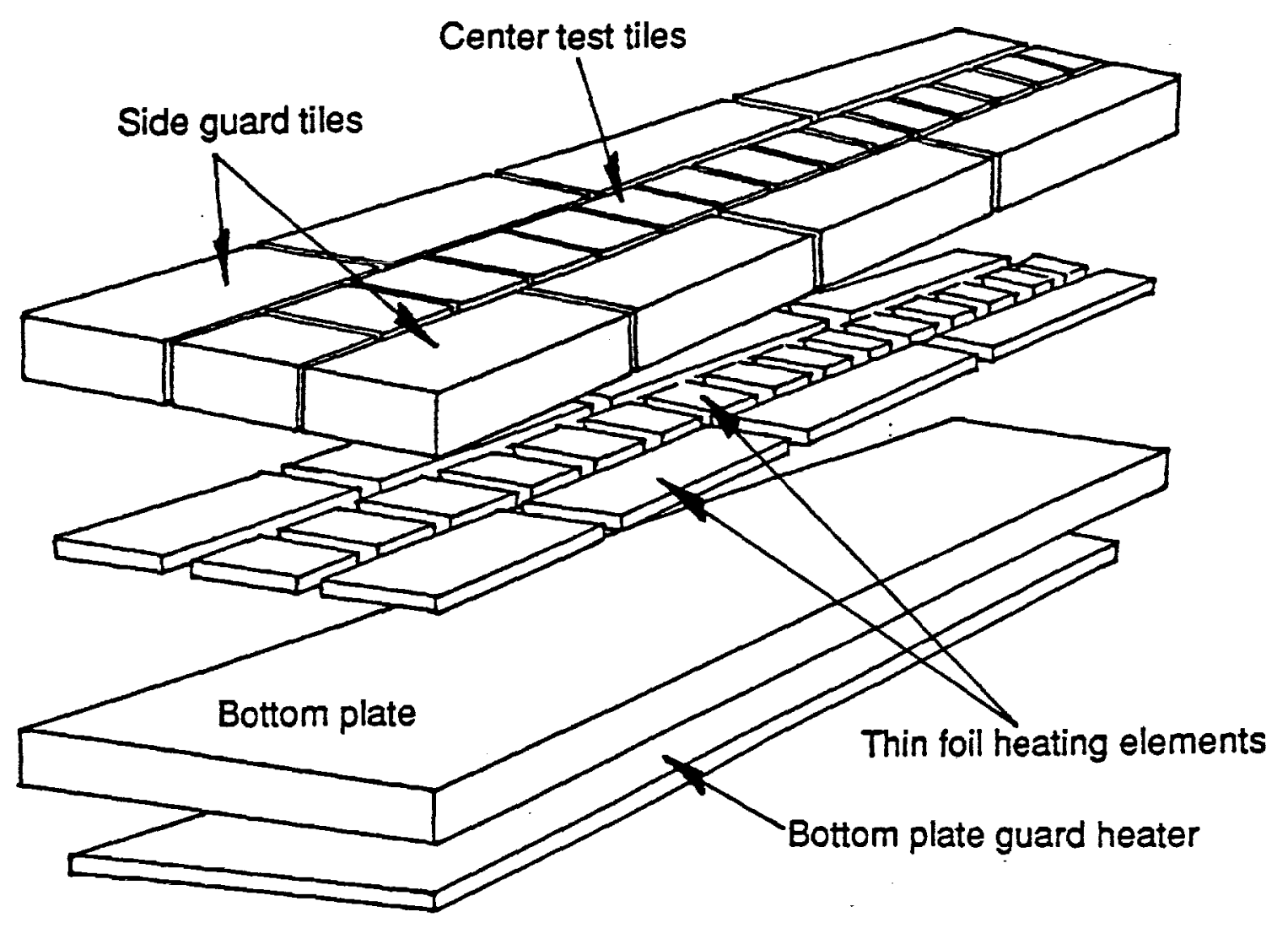

Fig. 1 Schematic of layout of individual components for the assembly of the heat transfer model.
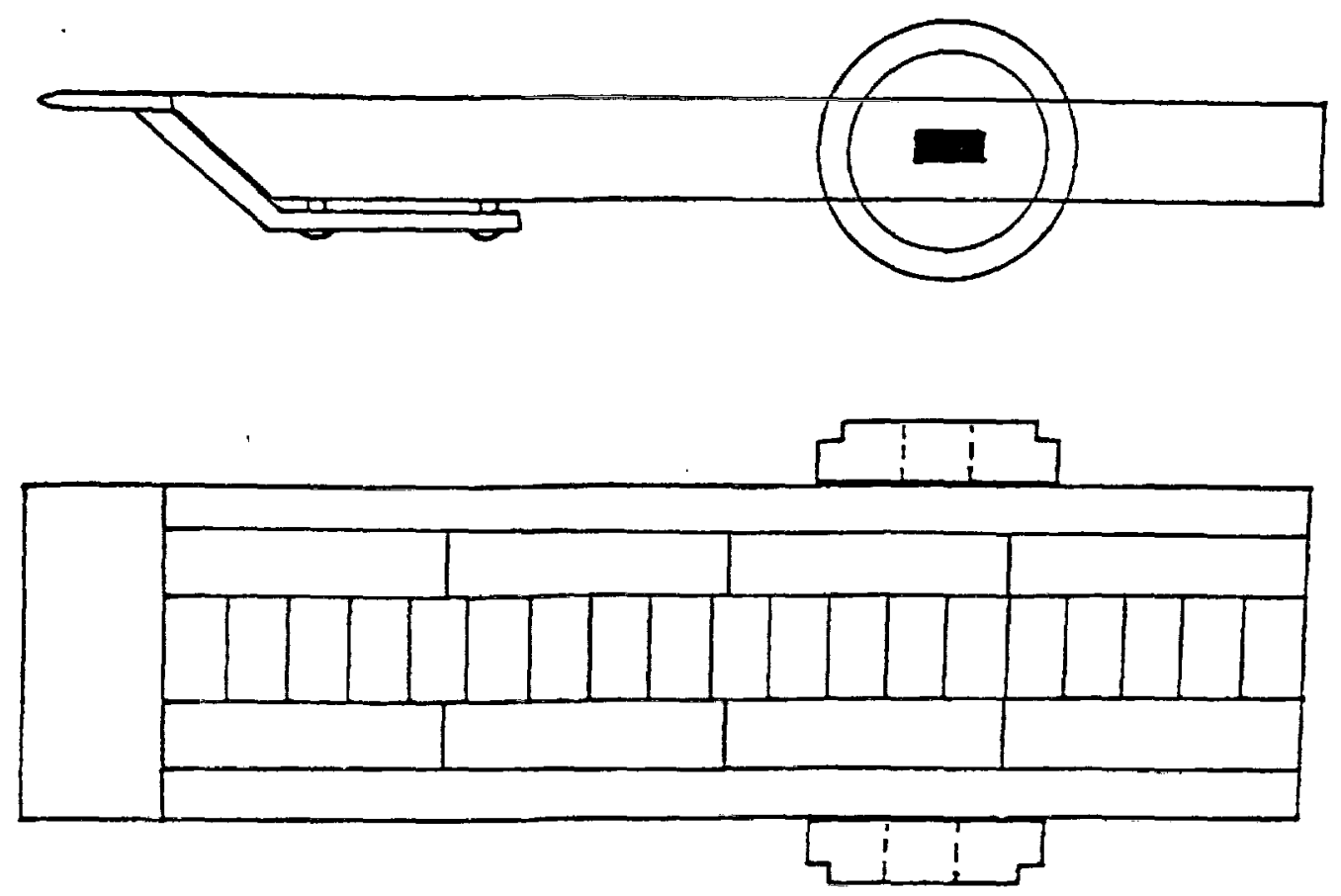

Fig. 2 Top and side views of heat transfer model installed in saddle. 


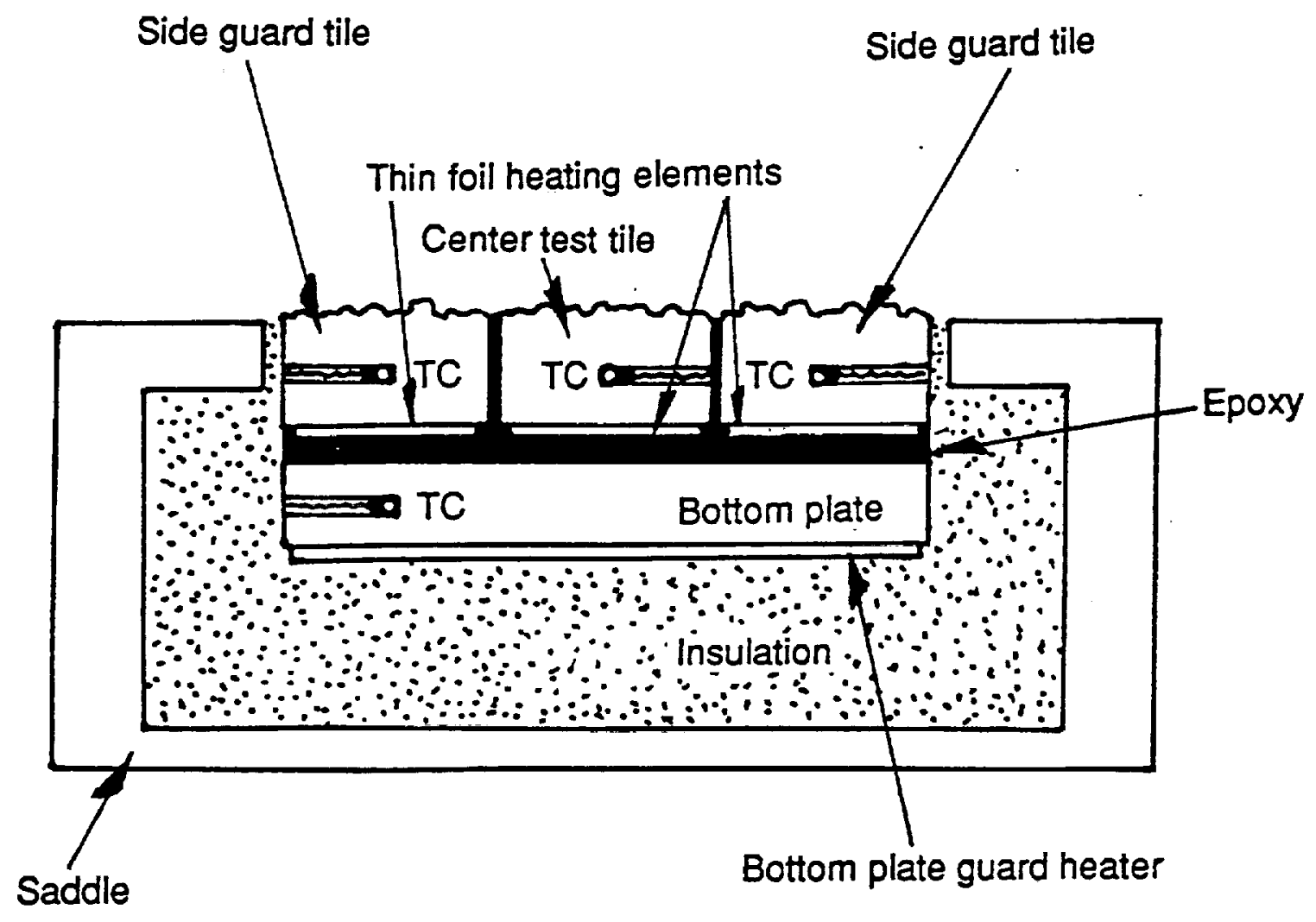

Fig. 3 Sectional view of heat transfer model installed in saddle. 


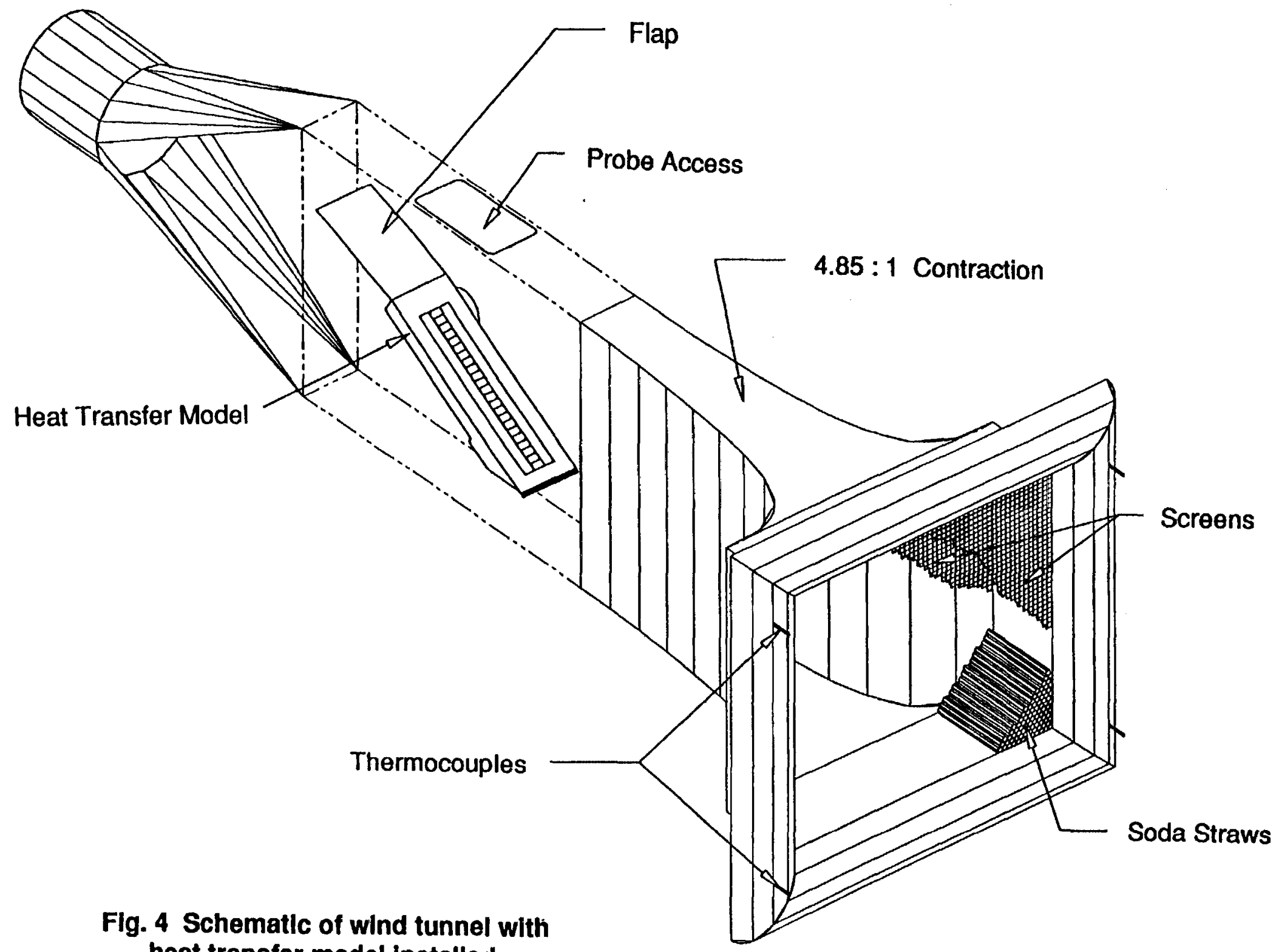
heat transfer model installed. 


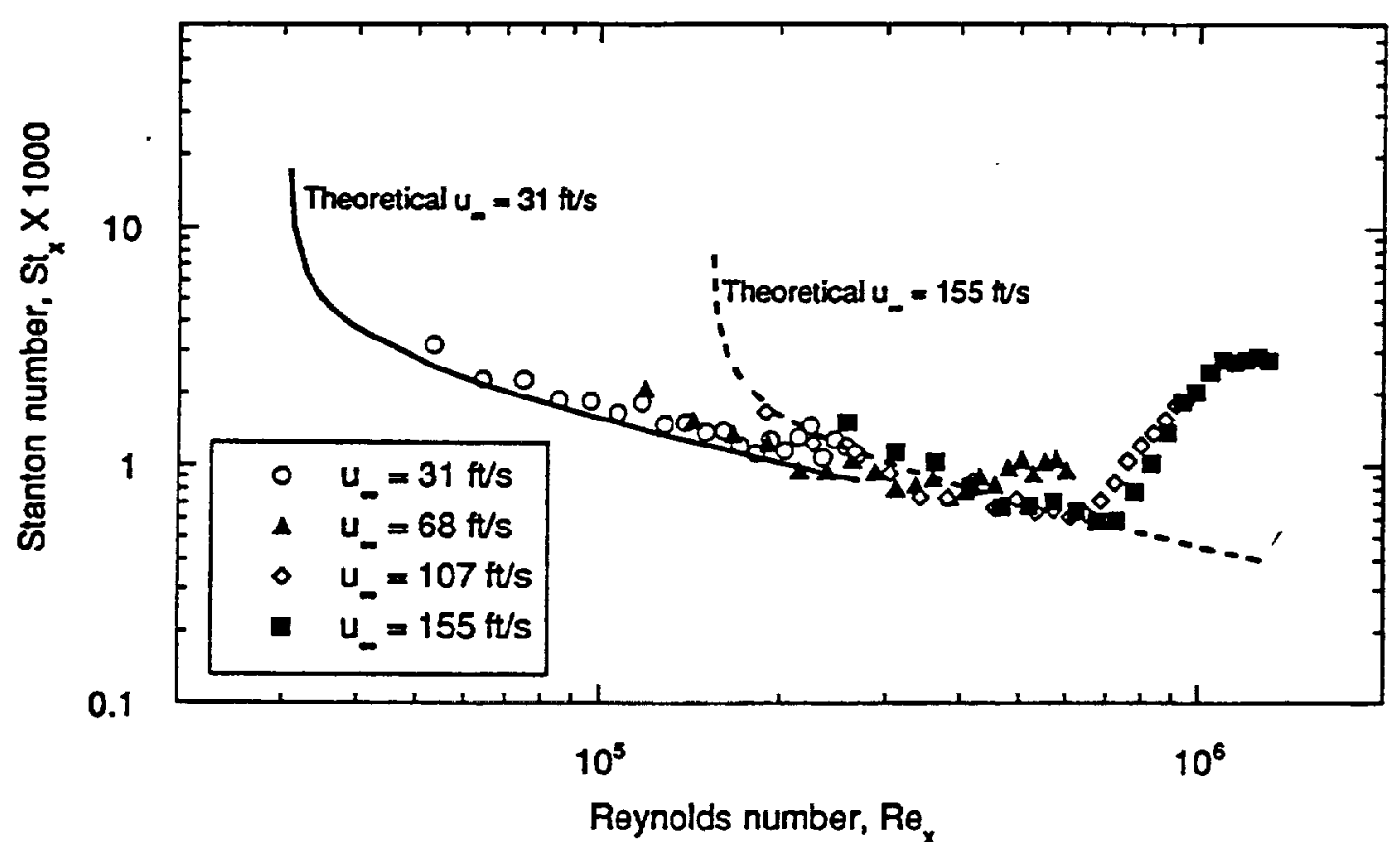

Fig. 5 Stanton number vs. Reynolds number. Smooth horlzontal plate at different free-stream velocities.

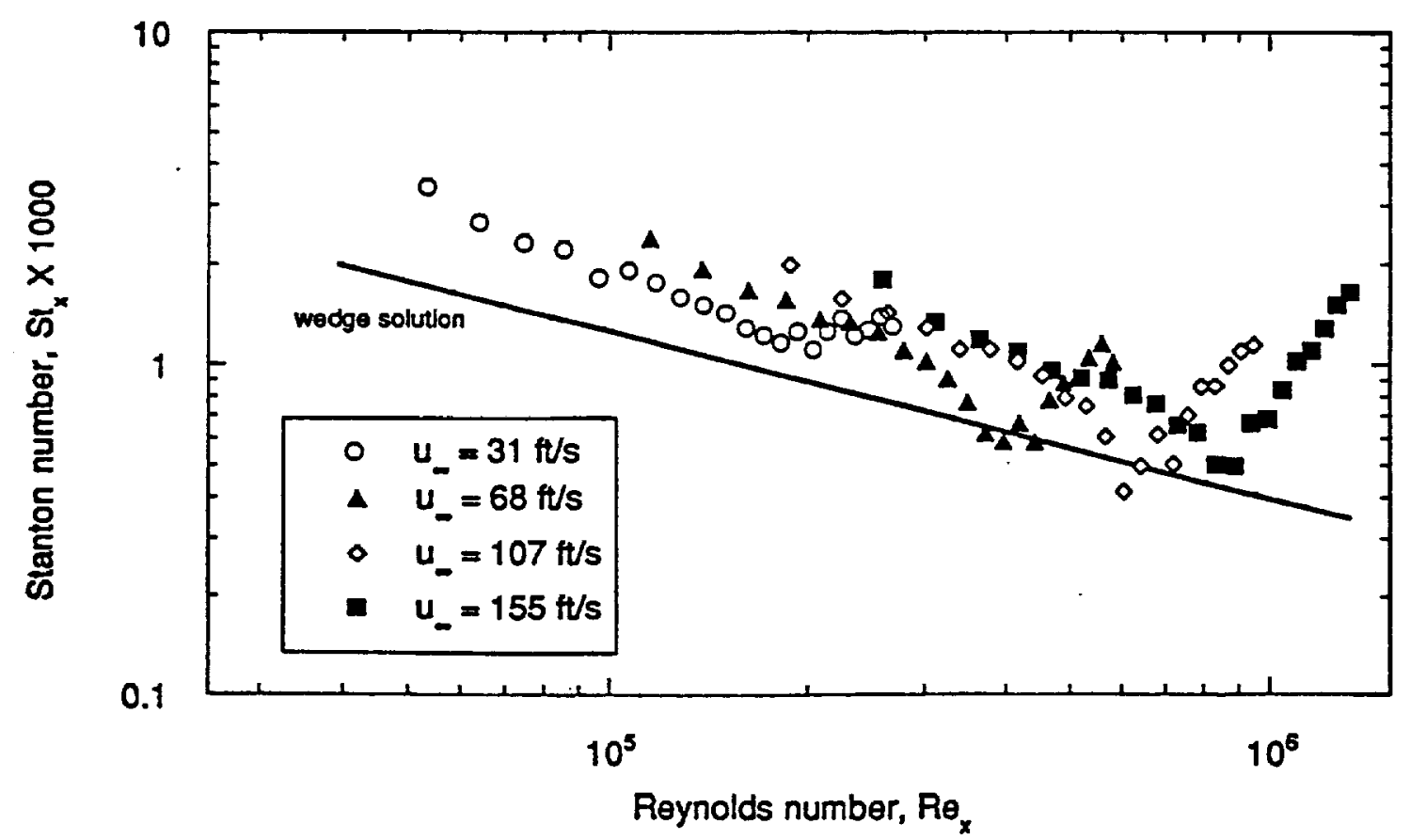

Fig. 6 Stanton number vs. Reynolds number. Smooth $14^{\circ}$-Inclined plate at different free-stream velocities. 


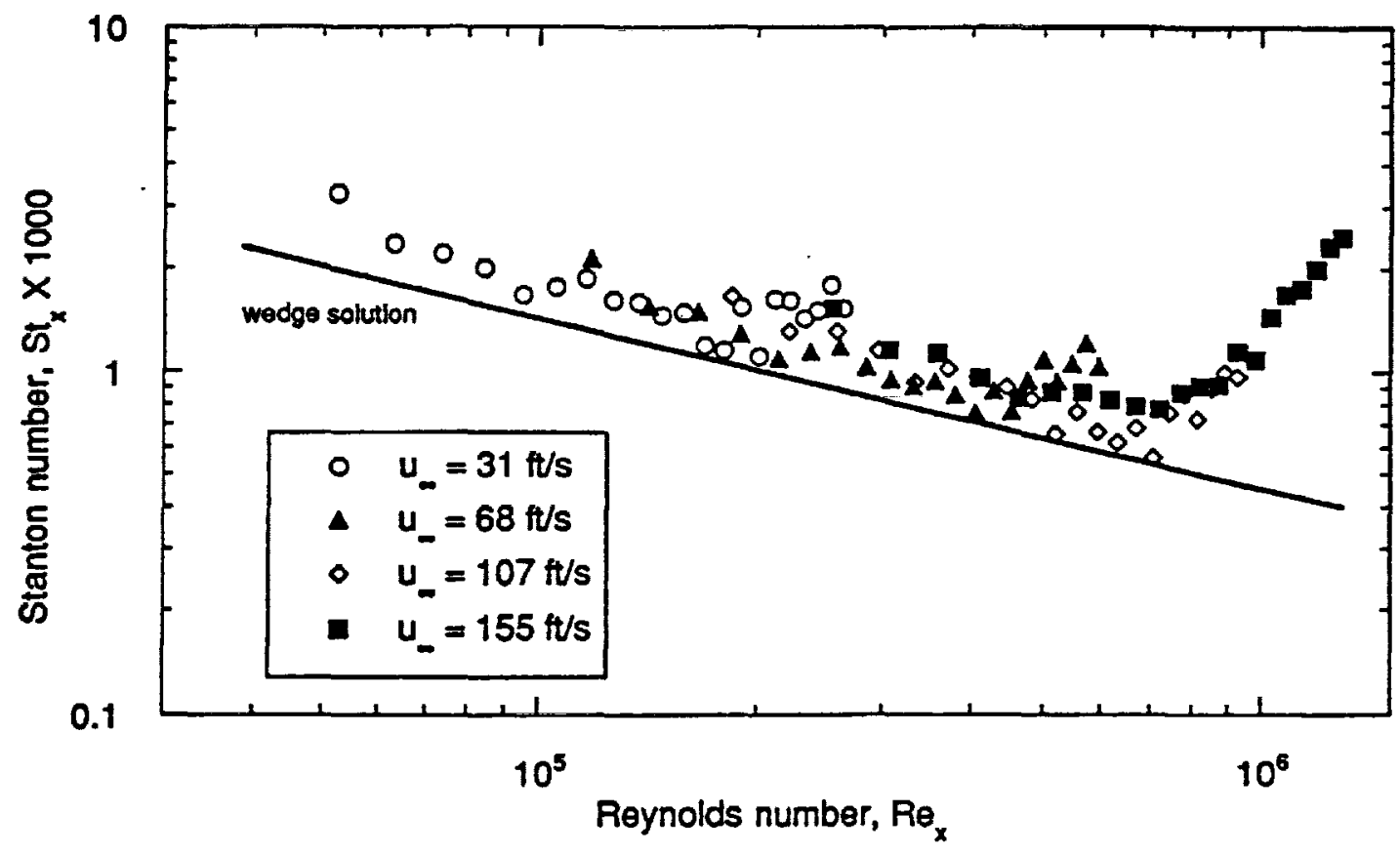

Fig. 7 Stanton number vs. Reynolds number.

Smooth $23^{\circ}$-inclined plate at different free-stream velocities.

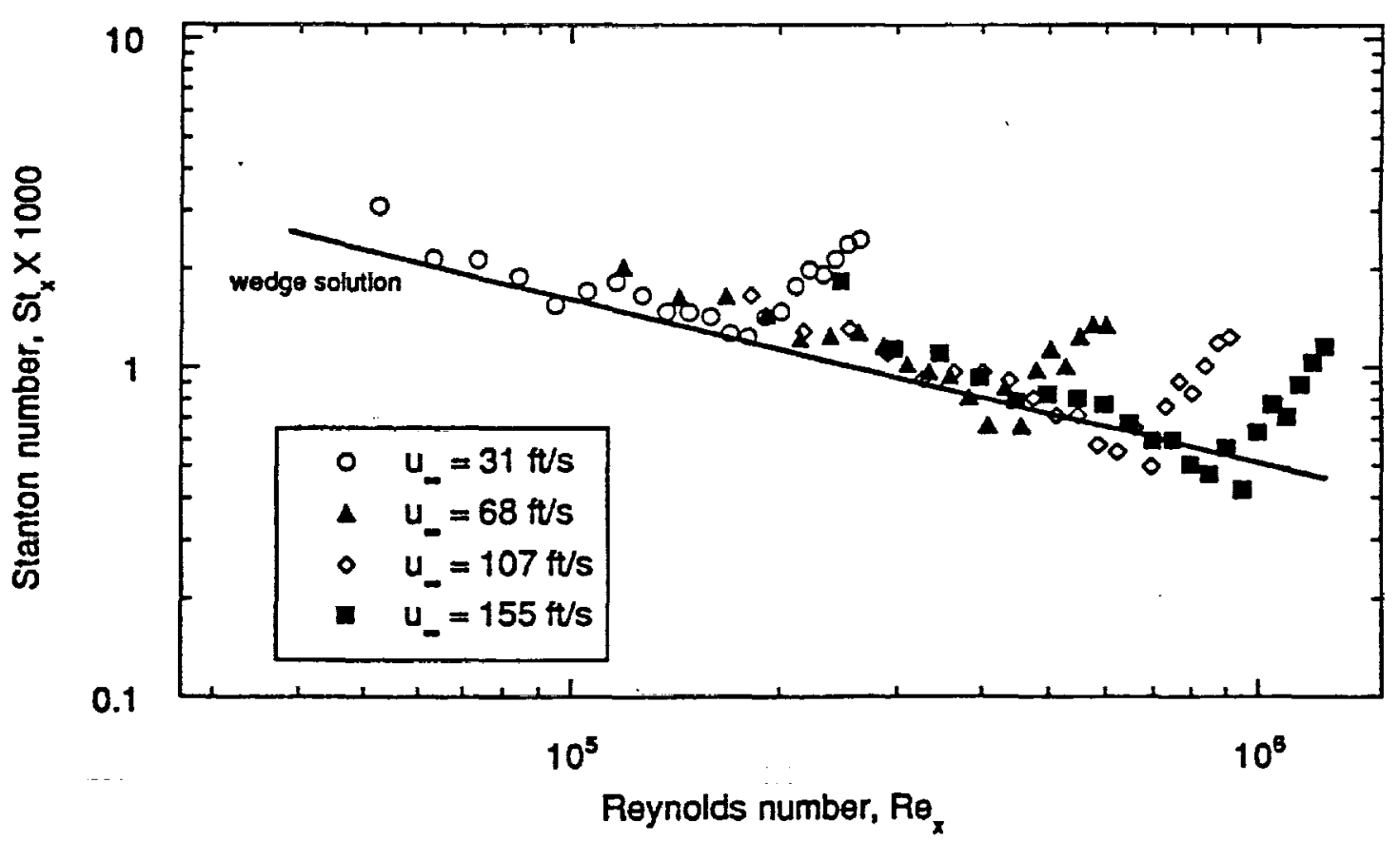

Fig. 8 Stanton number vs. Reynolds number. Smooth $32^{\circ}$-incilned plate at different free-stream velocities. 


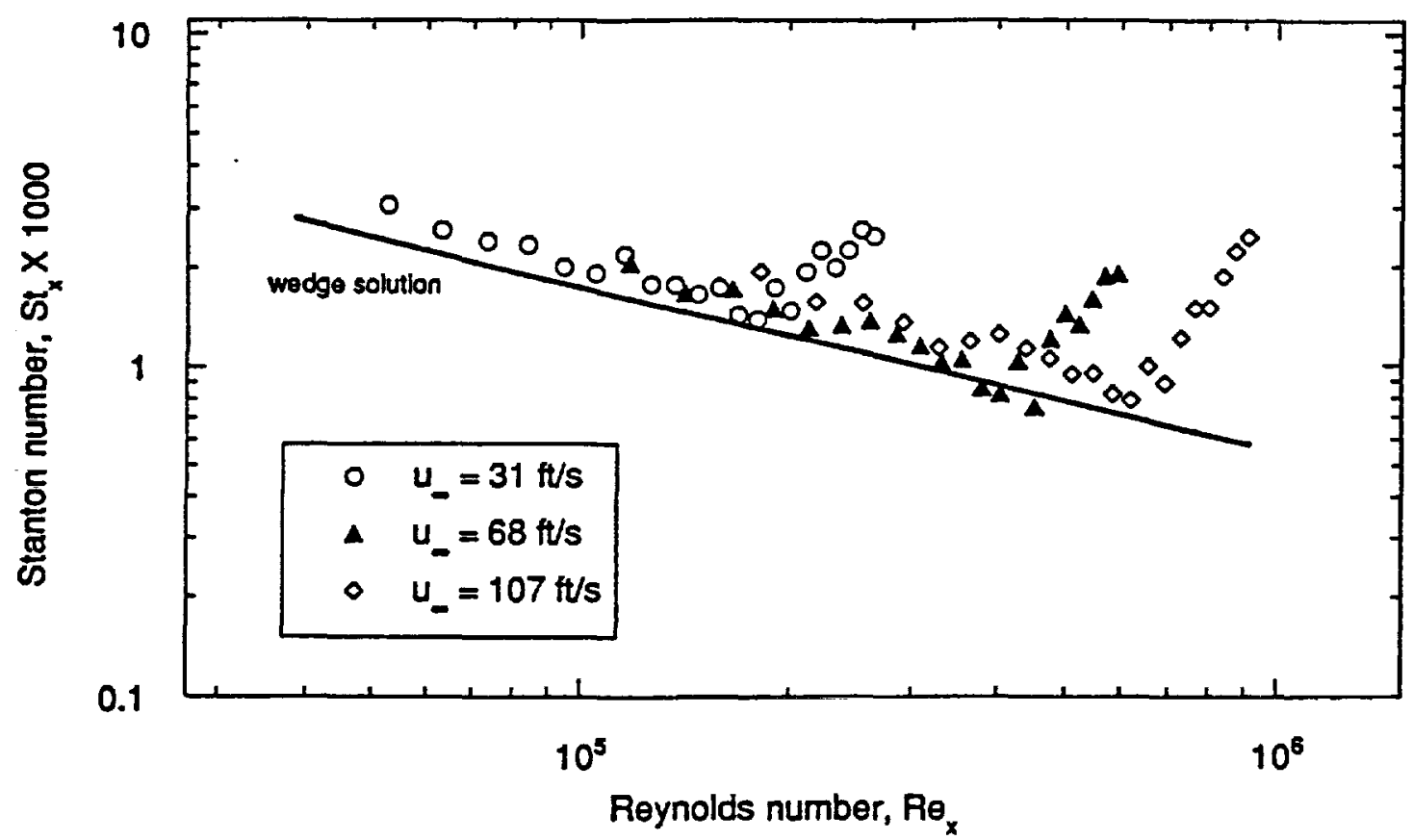

Fig. 9 Stanton number vs. Reynolds number.

Smooth $41^{\circ}$-inclined plate at different free-stream velocitles.

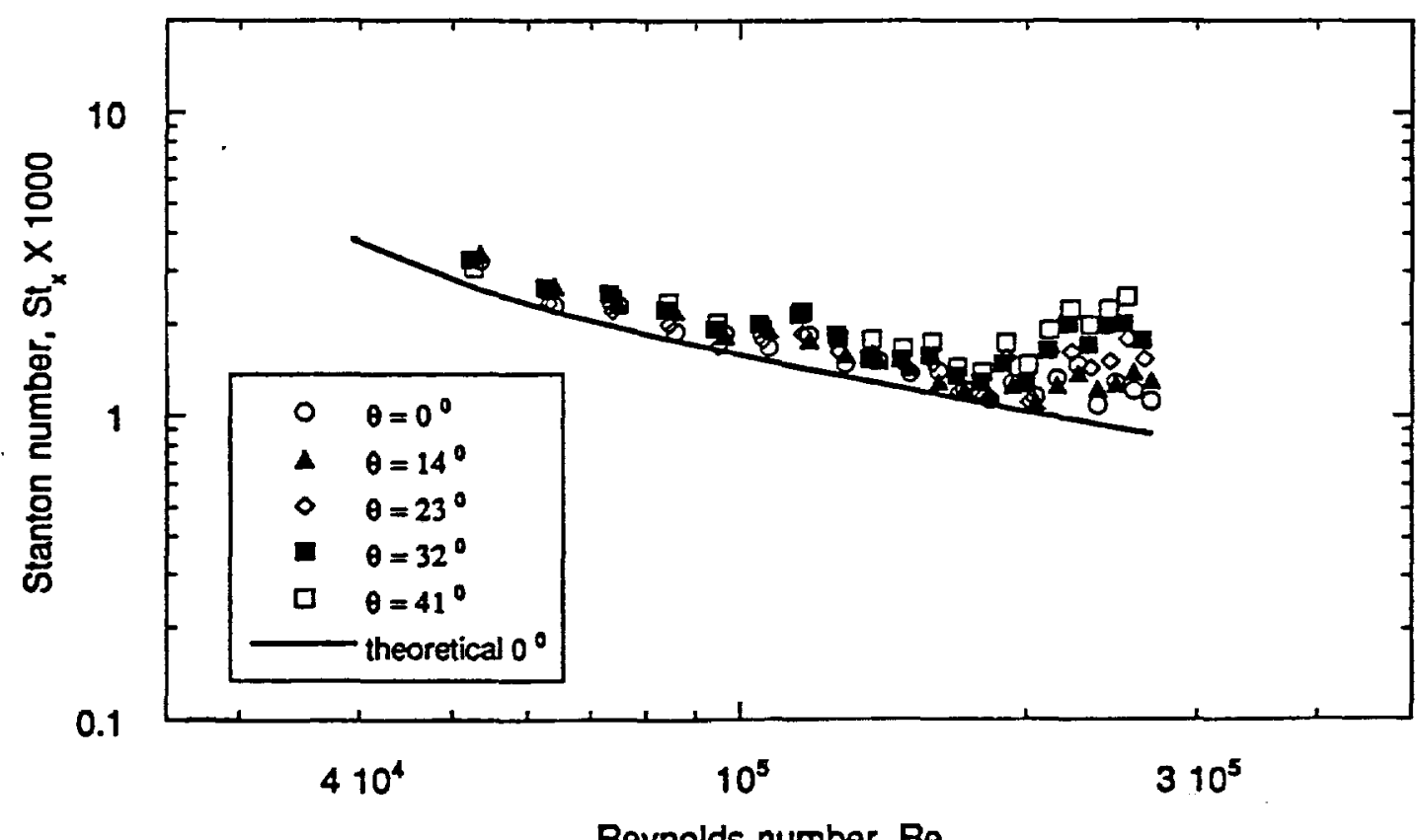

Flg.10 Stanton number vs. Reynolds number. Smooth plate at $u_{-}=31 \mathrm{ft} / \mathrm{s}$ and different angles. 


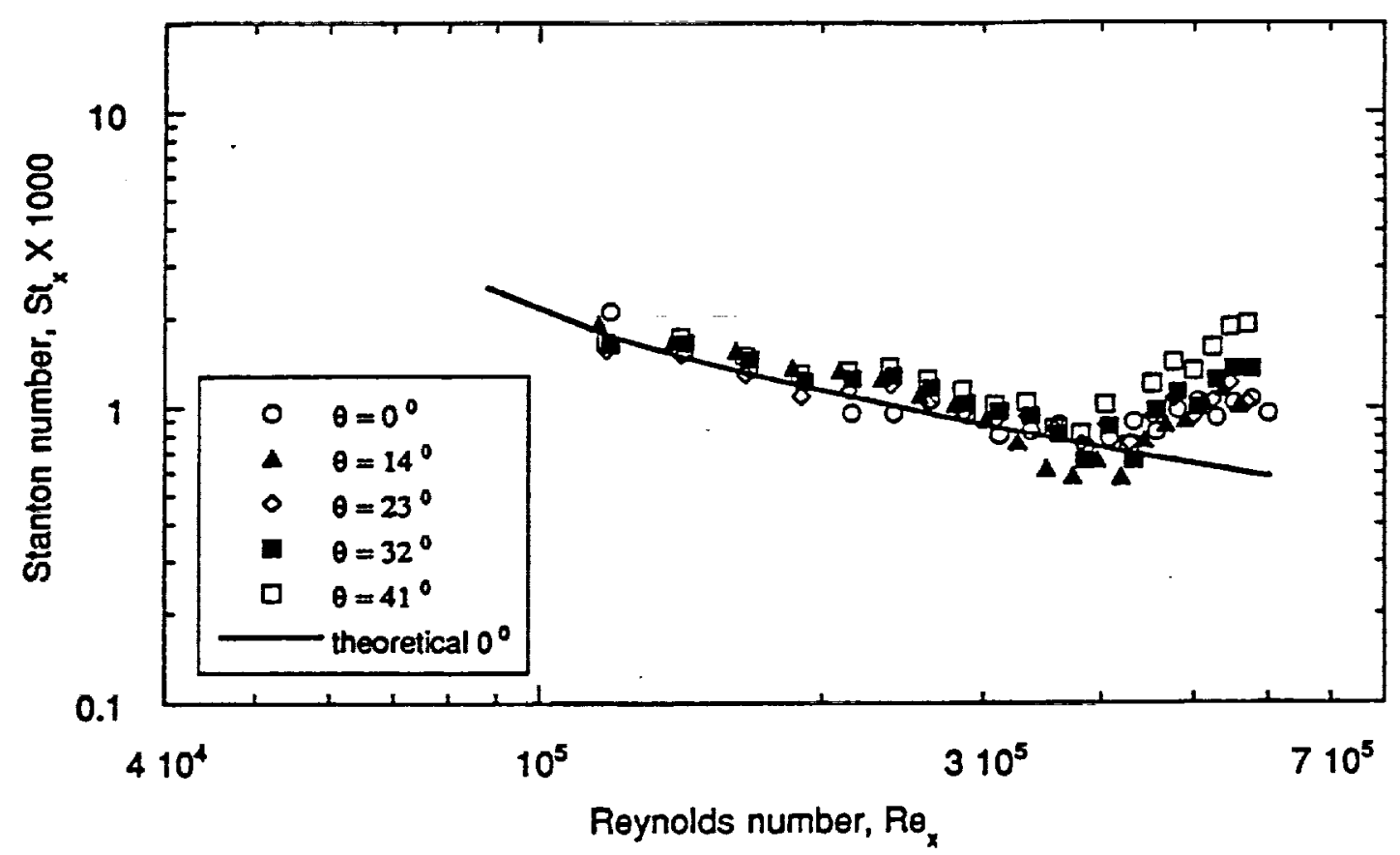

Fig.11 Stanton number vs. Reynolds number. Smooth plate at $u_{-}=68 \mathrm{ft} / \mathrm{s}$ and different angles.

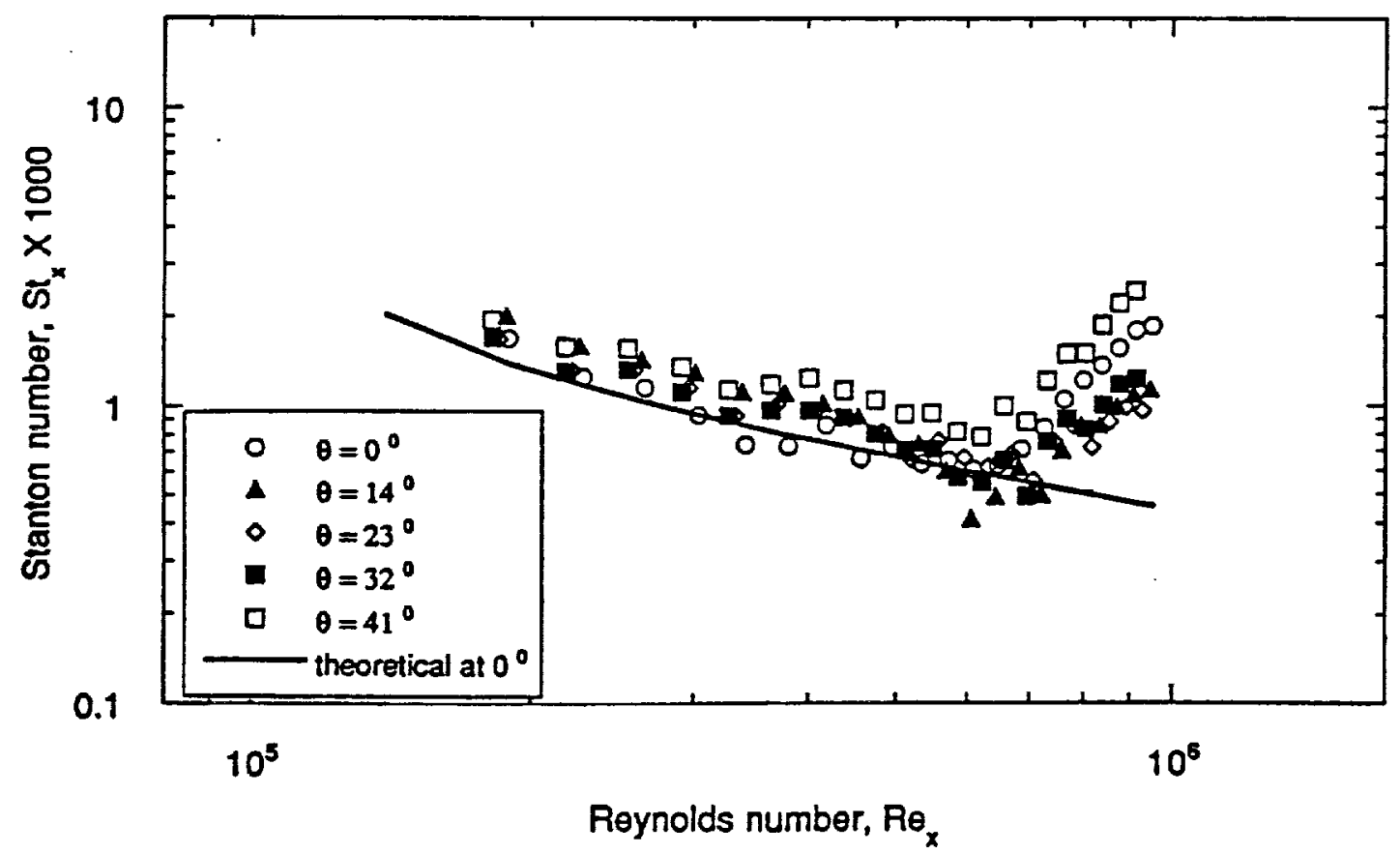

Fig. 12 Stanton number vs. Reynolds number. Smooth plate at $u_{-}=107 \mathrm{ft} / \mathrm{s}$ and different angles. 


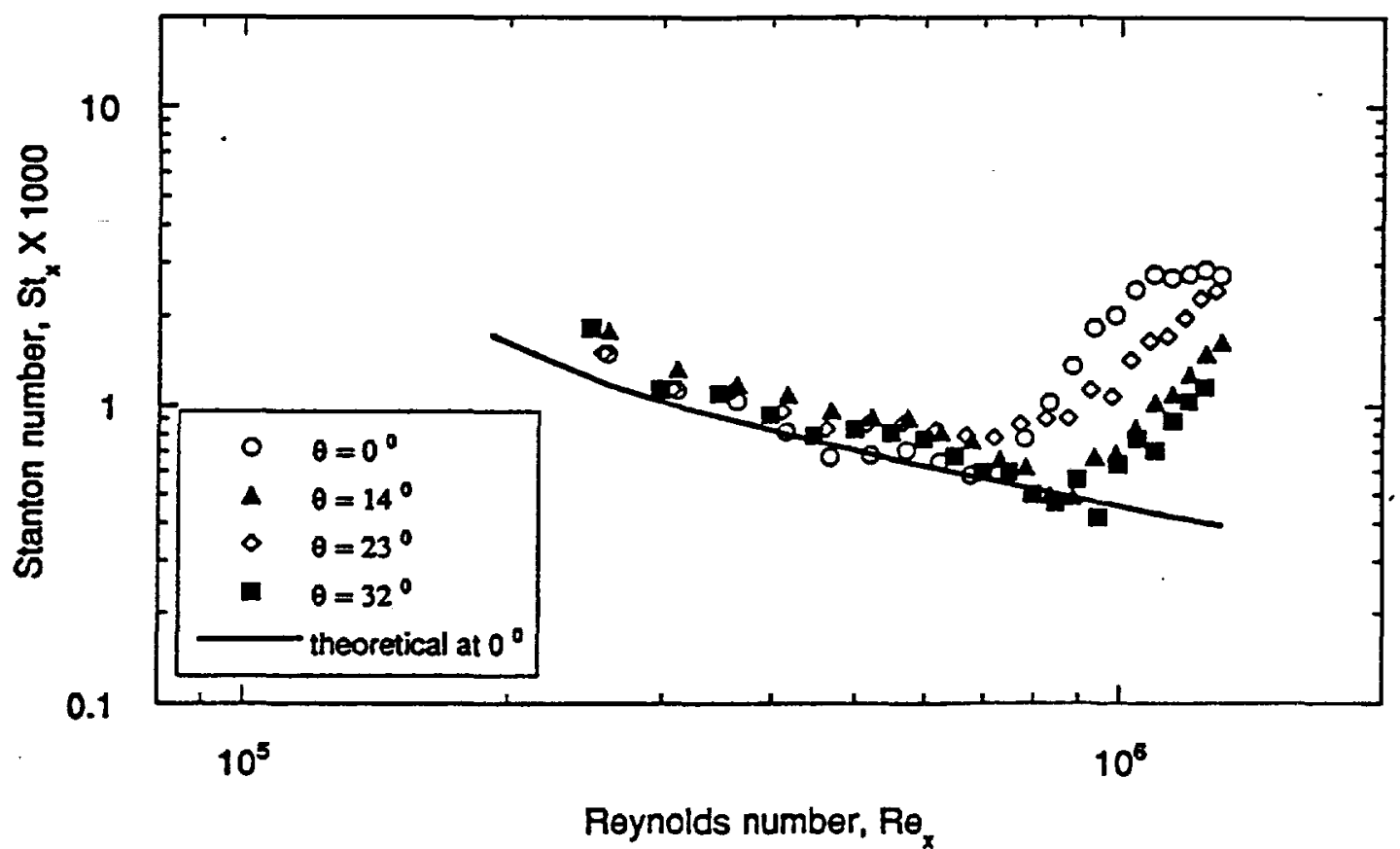

Fig.13 Stanton number vs. Reynolds number. Smooth plate at $u_{-}=155 \mathrm{tt} / \mathrm{s}$ and different angles. 


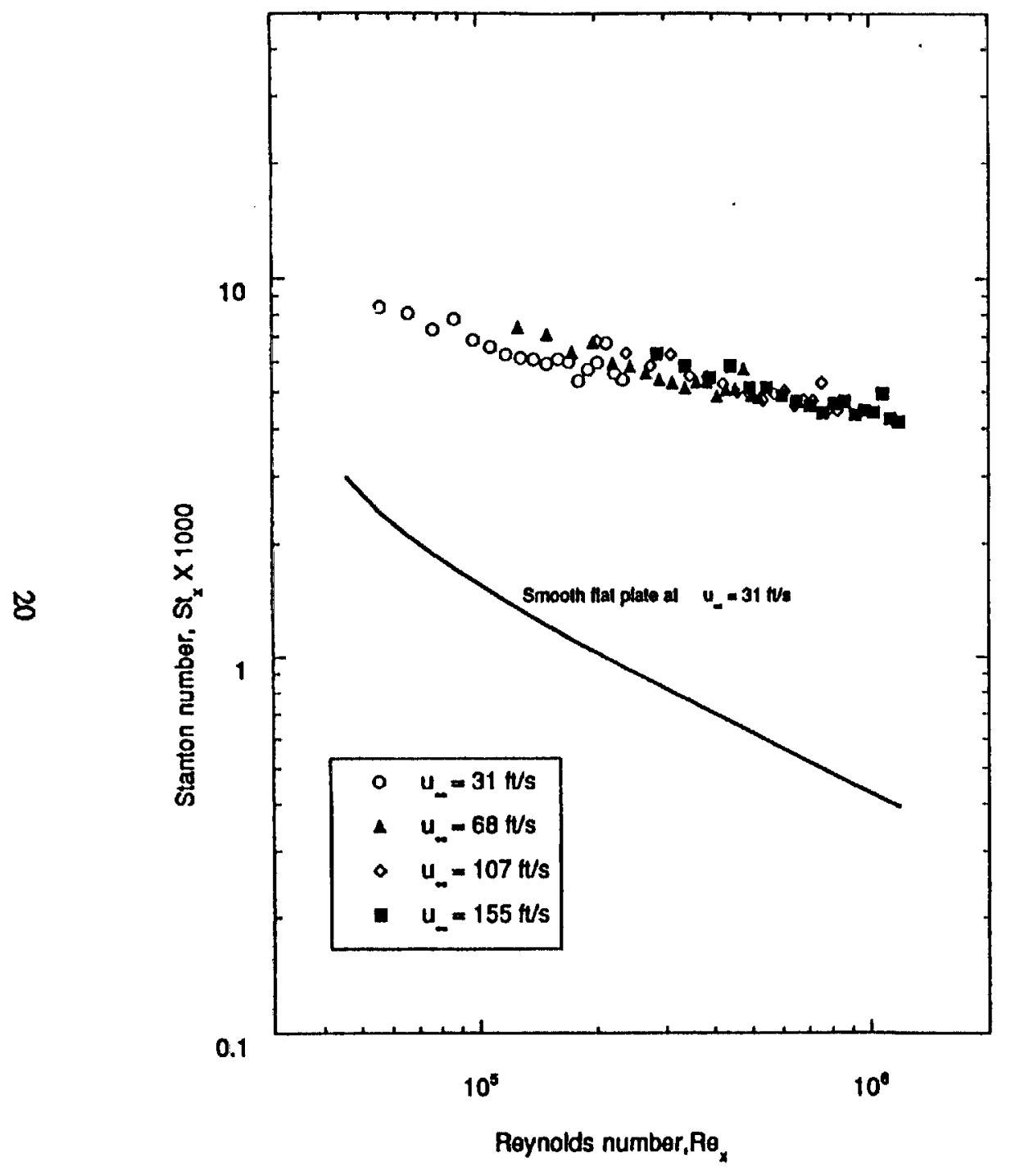

Flg.14 Stantan number vs. Roynolds number. Rough horizontal plate at different free-stream velocitles.

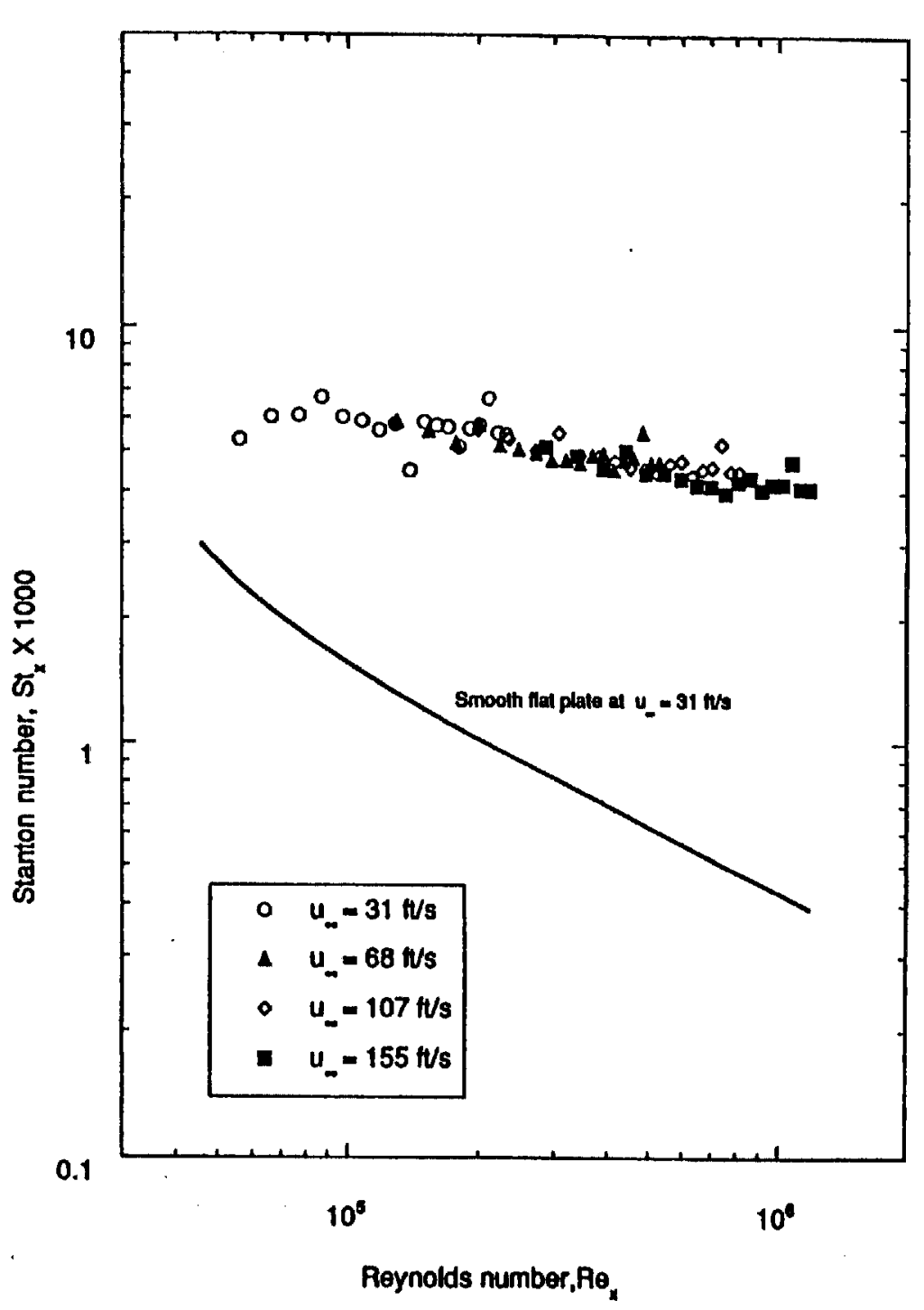

Fig.15 Stanton number vs. Reynolds number. Rough $14^{\circ}$-Inclined plate at different frees-tream velocltles. 


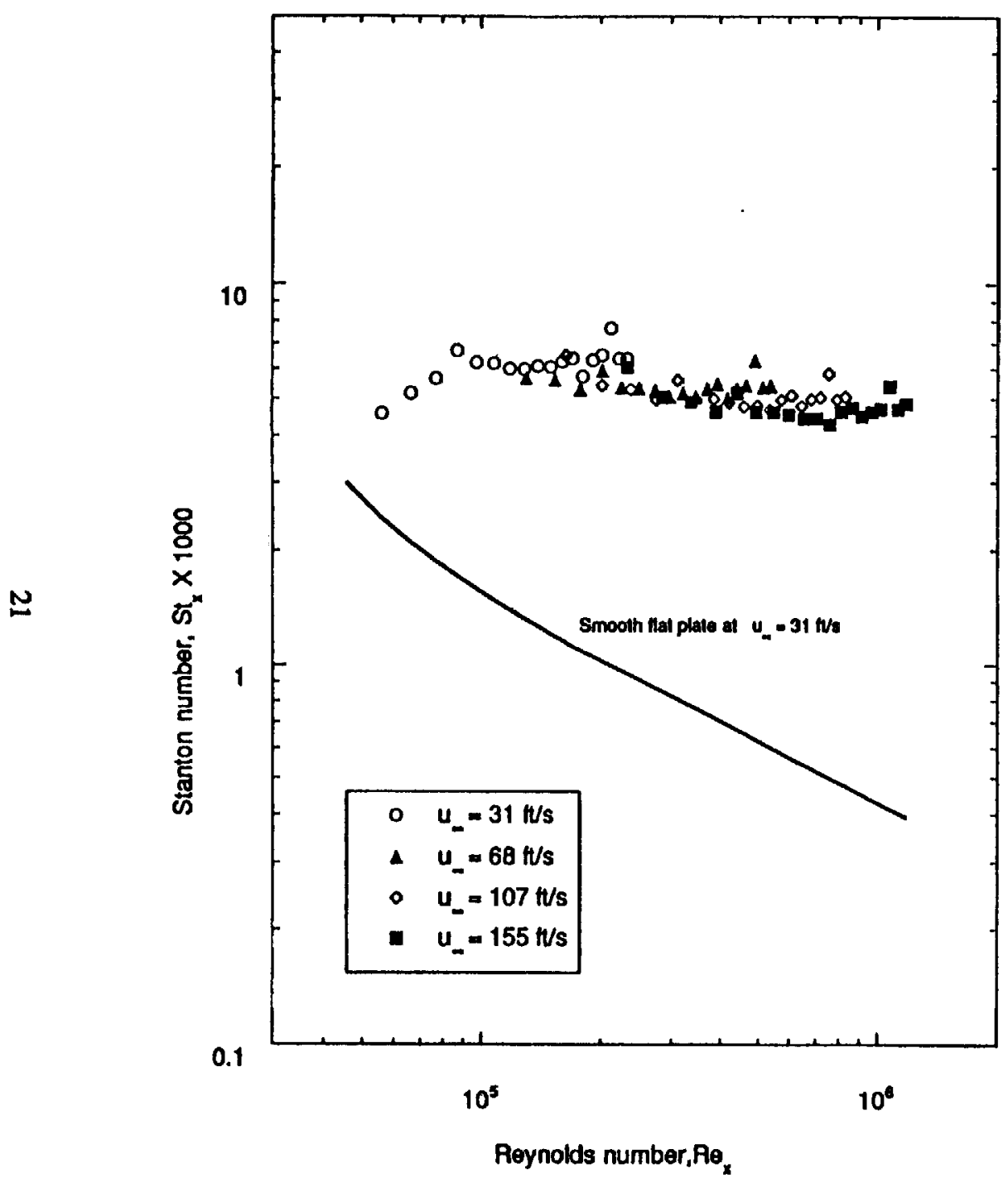

Flg.16 Stanton number vs. Reynolds number. Rough $23^{\circ}$-Inclined plate at different frees-treem velocilles.

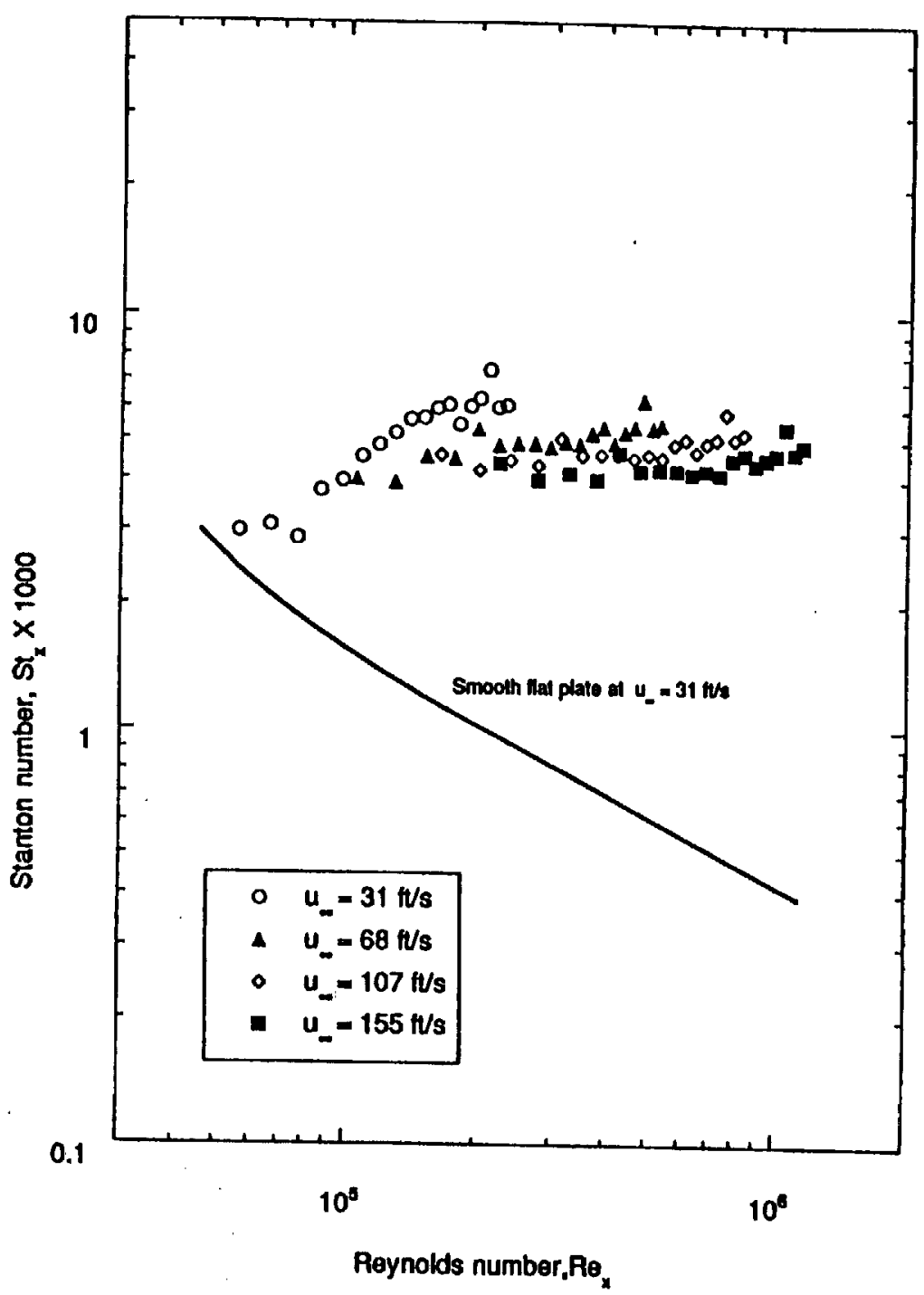

Fig.17 Stanton number vs. Reynolds number. Rough $32^{\circ}$-Inclined plate at dilferent free-stream velocilies. 


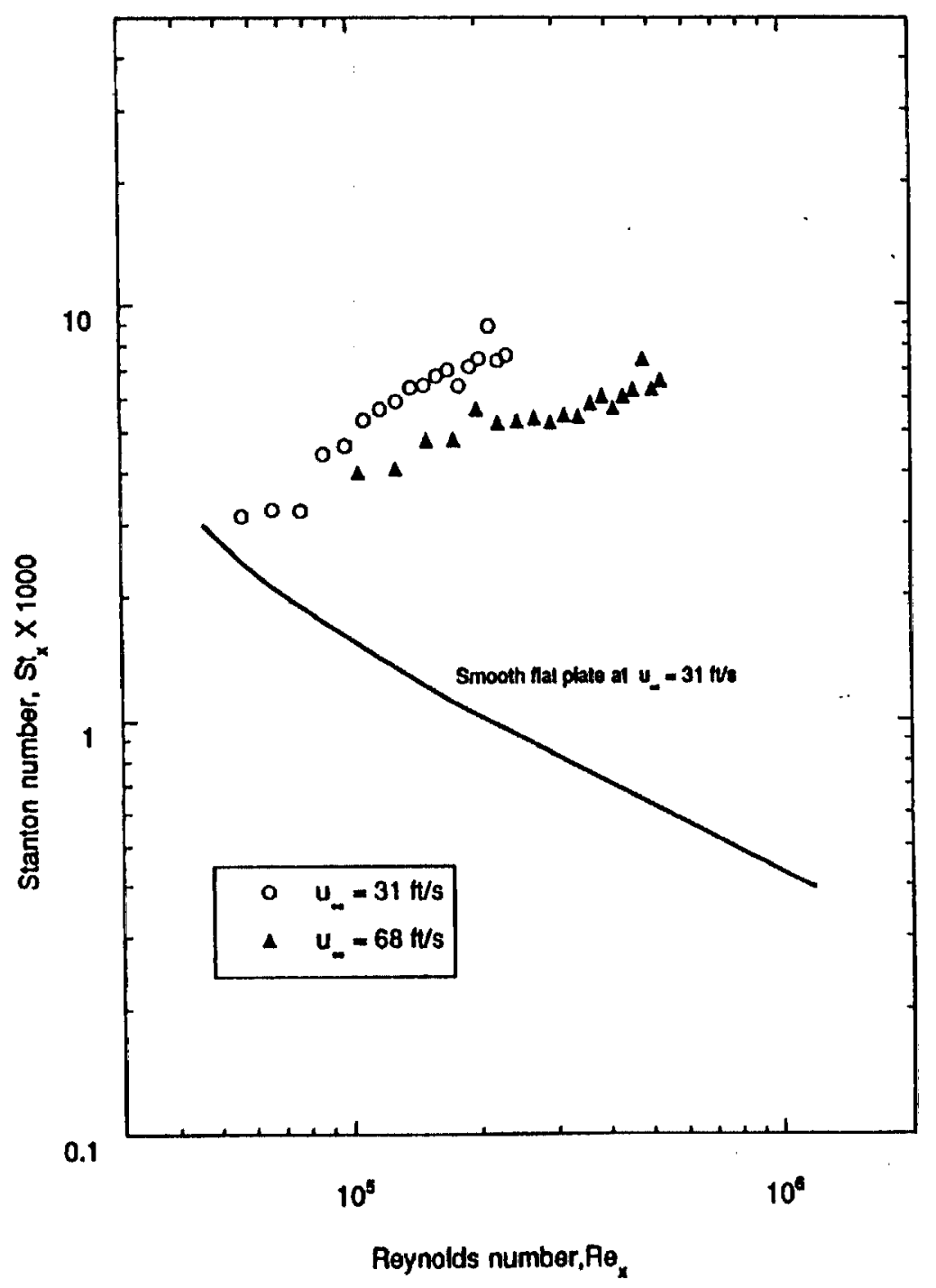

Fig.18 Stanton number vs. Reynolds number. Rough $41^{\circ}$-Inclined plate at dilferent treo-stream velocitles.

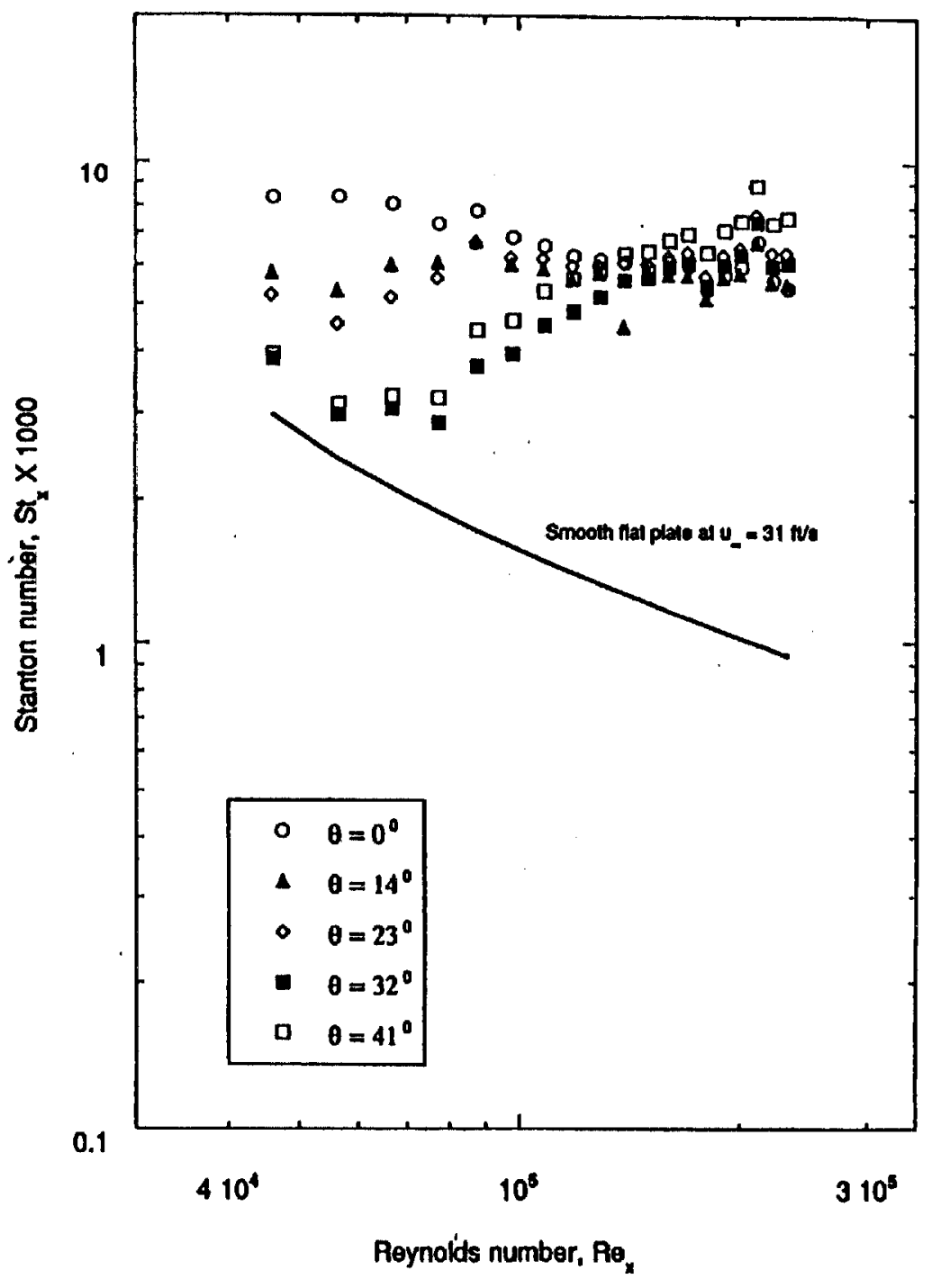

Fig.19 Stenton number vs. Reynolds number. Rough plate at $u_{-}=31 \mathrm{tt} / \mathrm{s}$ and different angles. 


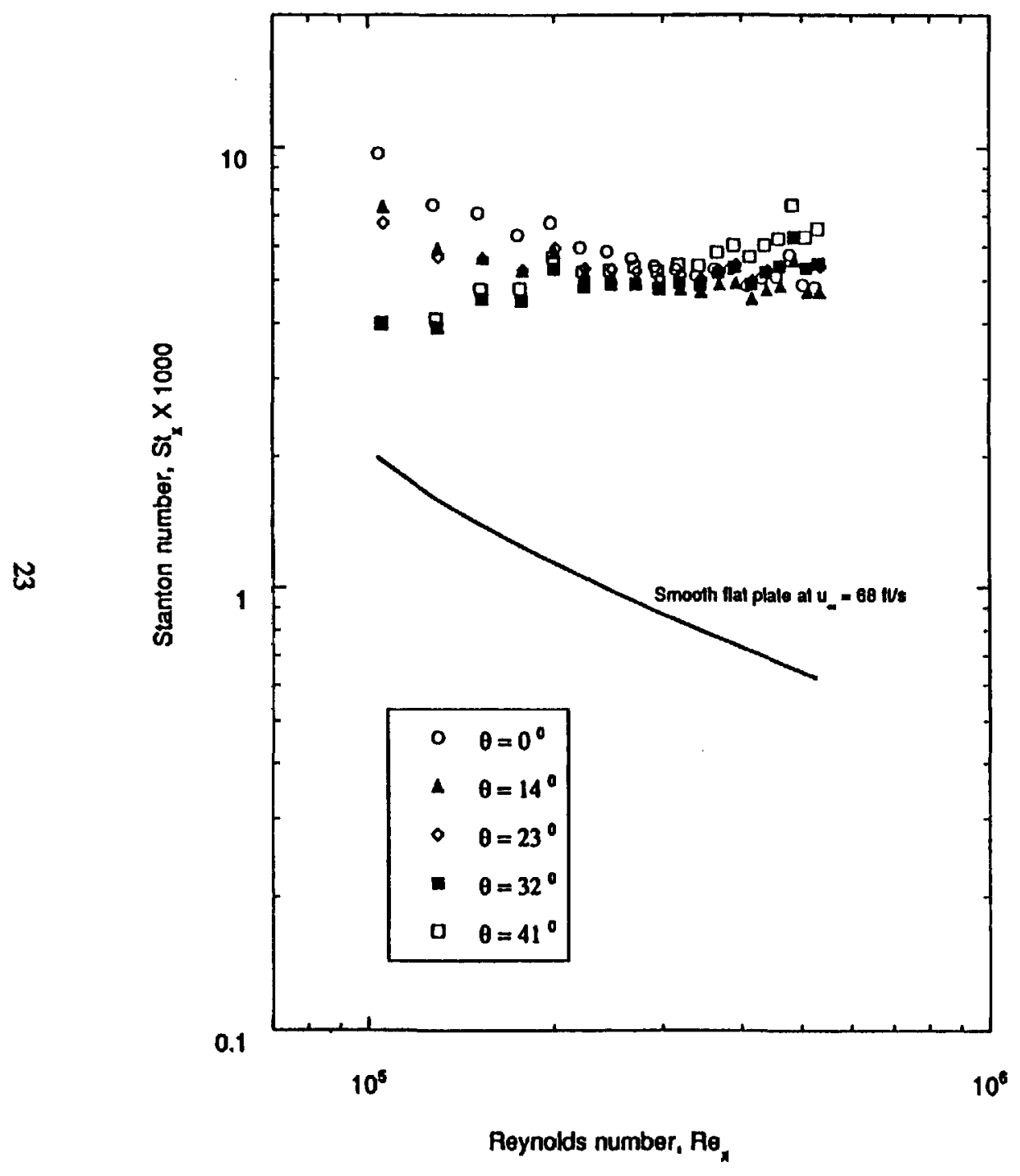

Fig.20 Stanton number vs. Reynolds number. Rough plate at $u_{-}=68 \mathrm{ft} / \mathrm{s}$ and different angles.

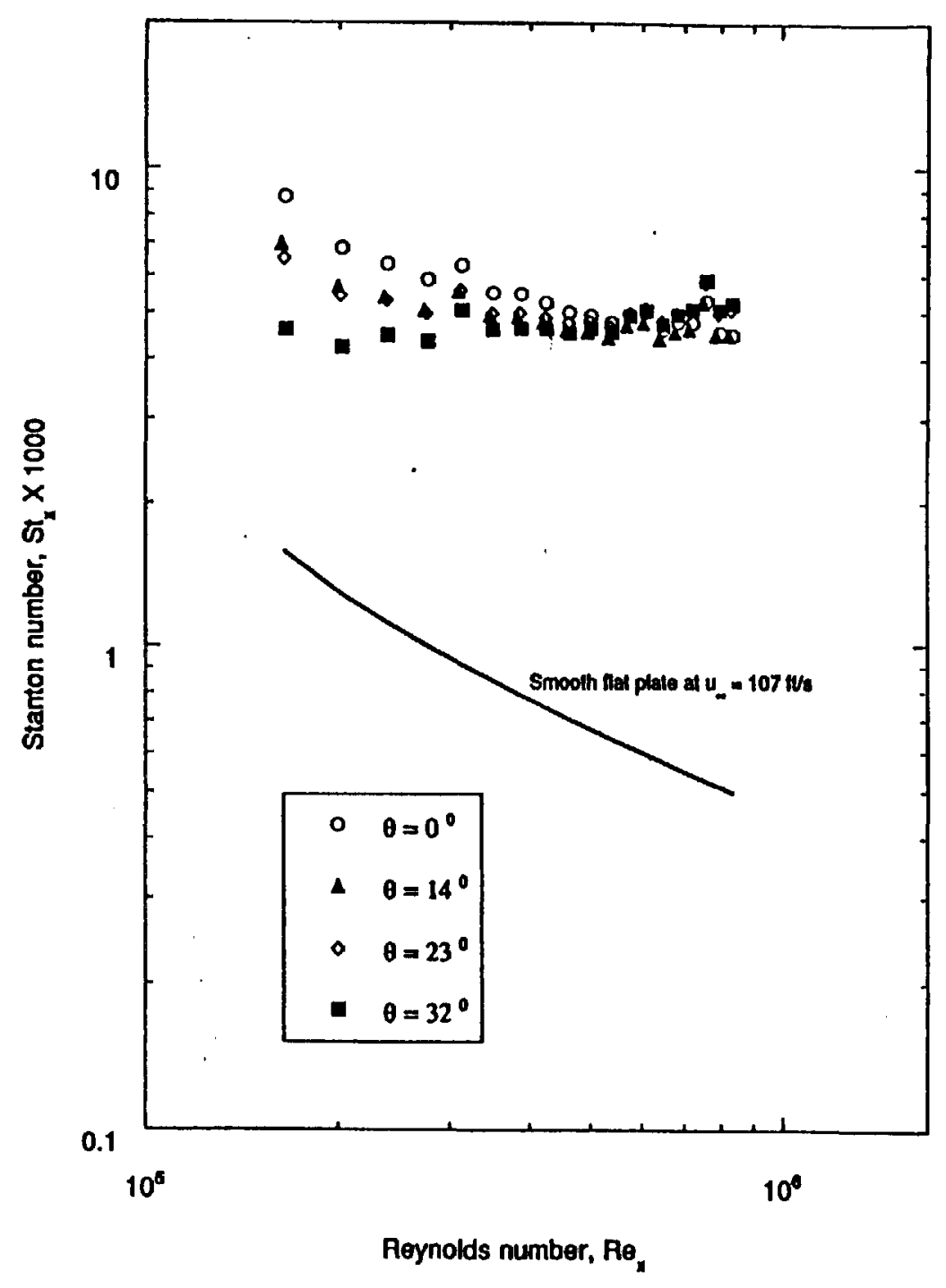

Flg.21 Stanton number vs. Reynolds number. Rough plate at $u_{-}=107 \mathrm{t} / \mathrm{s}$ and different angles. 


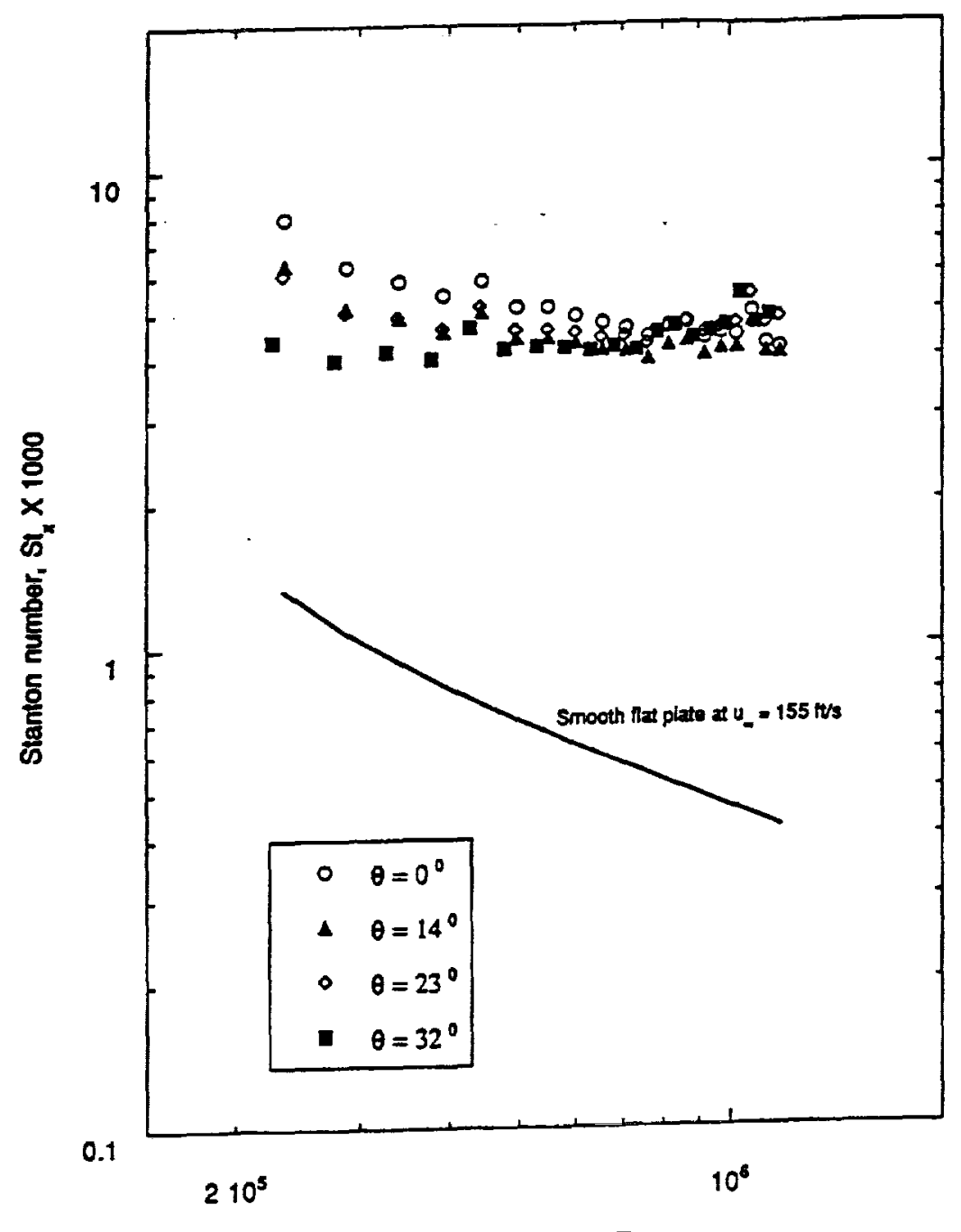

Reynolds number, $R \theta_{x}$

Fig.22 Stanton number vs. Reynolds number. Rough plate at $u_{-}=155 \mathrm{tt} / \mathrm{s}$ and different angles. 


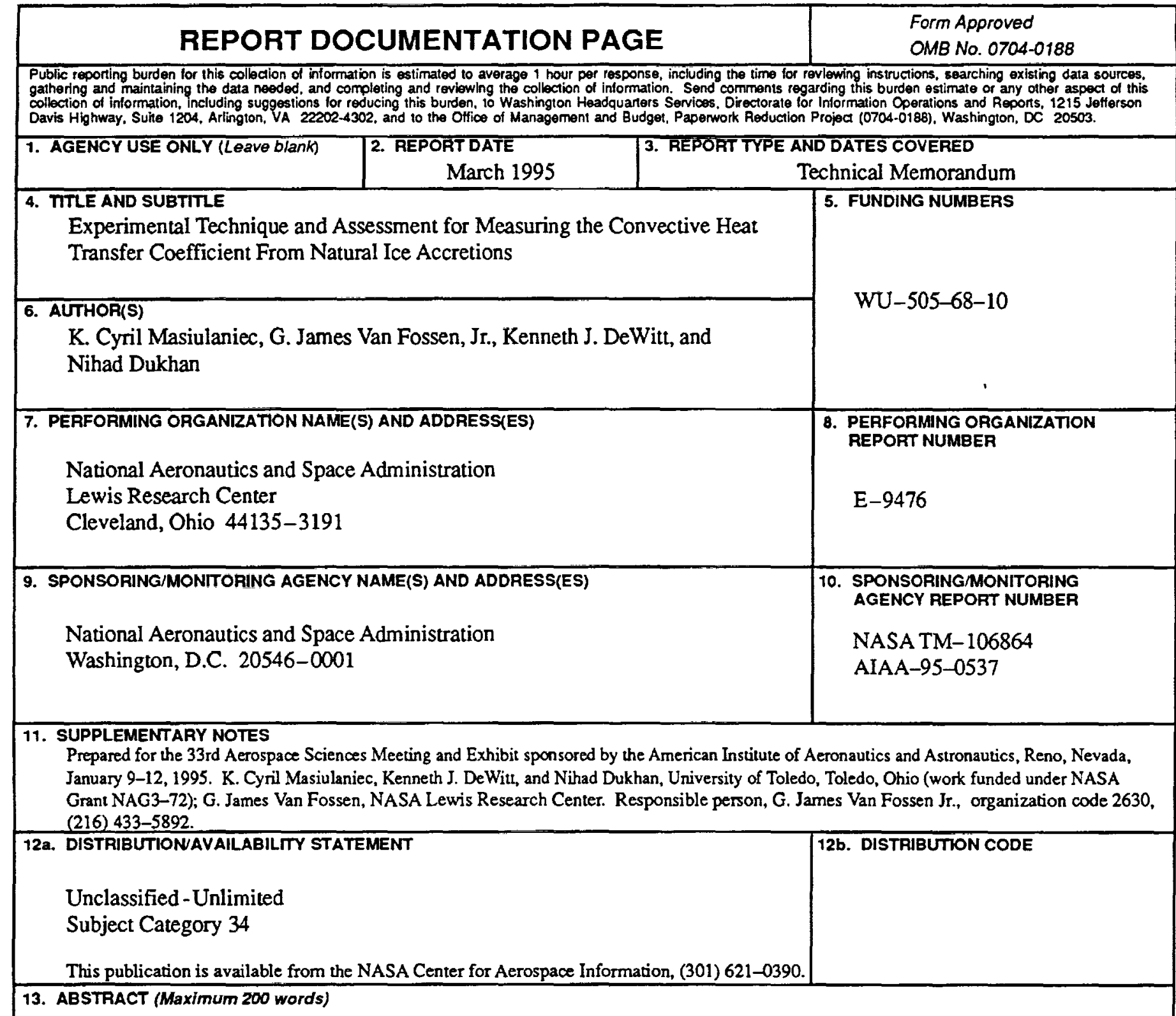

A technique was developed to cast frozen ice shapes that had been grown on a metal surface. This technique was applied to a series of ice shapes that were grown in the NASA Lewis Icing Research Tunnel on flat plates. Nine flat plates, 18 inches square, were obtained from which aluminum castings were made that gave good ice shape characterizations. Test strips taken from these plates were outfitted with heat flux gages, such that when placed in a dry wind tunnel, can be used to experimentally map out the convective heat transfer coefficient in the direction of flow from the roughened surfaces. The effects on the heat transfer coefficient for both parallel and accelerating flow will be studied. The smooth plate model verification baseline data as well as one ice roughened test case are presented.

\begin{tabular}{|c|c|c|}
\hline \multicolumn{3}{|c|}{$\begin{array}{l}\text { 14. SUBJECT TERMS } \\
\text { Heat transfer; Aircraft icing }\end{array}$} \\
\hline $\begin{array}{l}\text { 17. SECURTY CLASSIFICATION } \\
\text { OF REPORT } \\
\text { Unclassified }\end{array}$ & $\begin{array}{l}\text { 18. SECURITY CLASSIFICATION } \\
\text { OF THIS PAGE } \\
\text { Unclassified }\end{array}$ & $\begin{array}{l}\text { 19. SECURITY CLASSIFICATION } \\
\text { OF ABSTRACT } \\
\text { Unclassified }\end{array}$ \\
\hline
\end{tabular}

